\title{
Nutritional characterisation of low-income households of Nairobi: socioeconomic, livestock and gender considerations and predictors of malnutrition from a cross- sectional survey
}

Paula Dominguez-Salas ${ }^{1,2,3^{*}}$, P. Alarcón ${ }^{1,3}$, B. Häsler ${ }^{1,3}$, I. R. Dohoo ${ }^{4}$, K. Colverson ${ }^{5}$, E. W. Kimani-Murage ${ }^{6}$, S. Alonso ${ }^{2}$, E. Ferguson ${ }^{3,7}$, E. M. Fèvre ${ }^{2,8}$, J. Rushton ${ }^{1,3}$ and D. Grace ${ }^{2}$

\begin{abstract}
Background: In sub-Saharan Africa, urban informal settlements are rapidly expanding, leading to overcrowding and constituting challenging environments for food and water supplies, health and nutrition. The study objectives were to characterise and compare two low-income areas of Nairobi according to socioeconomic (including livestock and gender) indicators and the nutritional status of non-pregnant women of reproductive age and 1 to 3 year-old children; and to investigate socioeconomic predictors of malnutrition in these areas.

Methods: In this cross-sectional survey 205 low-income households in deprived areas of Dagoretti and Korogocho (Nairobi) were randomly selected. Socioeconomic data were collected via an interviewer-administered questionnaire. Maternal and child dietary data were collected by a 24-h dietary recall. Maternal and child anthropometric and haemoglobin measurements were taken. Chi-square, t-test and Wilcoxon-Mann-Whitney test were used to compare groups and multivariable linear regression to assess predictors of malnutrition.

Results: Dagoretti consistently showed better socioeconomic indicators including: income, education and occupation of household head, land ownership, housing quality and domestic asset ownership. Animal ownership was more than twice as high in Dagoretti as in Korogocho (53.0 \% vs $22.9 \%$ of households; $p$-value $<0.0001$ ). A double burden of malnutrition existed: $41.5 \%$ of children were stunted, and $29.0 \%$ of women were overweight. In addition, $74.0 \%$ of the children and $25.9 \%$ of the women were anaemic, and were at risk of inadequate intakes for a number of micronutrients. Nutritional status and nutrient intakes were consistently better in Dagoretti than Korogocho; height-for-age $(0.47$ Z-scores higher; $p$-value $=0.004)$, the minimum dietary diversity $(80.0 \%$ vs $57.7 \%$ in children, $p$-value $=0.001)$ and intakes of several nutrients were significantly higher. Positive predictors of maternal nutritional status were income, age and not having a premature delivery. Positive predictors of child nutritional status were area, household head education, mother not being married, female animal ownership and child's sex (female).

(Continued on next page)
\end{abstract}

\footnotetext{
* Correspondence: pdominguezsalas@rvc.ac.uk

${ }^{1}$ Veterinary Epidemiology, Economics and Public Health Group, Royal

Veterinary College, University of London, Hawkshead Lane, Hatfield,

Hertfordshire AL9 7TA, UK

${ }^{2}$ International Livestock Research Institute, Old Naivasha Rd, Nairobi 00100,

Kenya

Full list of author information is available at the end of the article
}

\section{$\int$ Biomed Central}

(c) 2016 The Author(s). Open Access This article is distributed under the terms of the Creative Commons Attribution 4.0 International License (http://creativecommons.org/licenses/by/4.0/), which permits unrestricted use, distribution, and reproduction in any medium, provided you give appropriate credit to the original author(s) and the source, provide a link to the Creative Commons license, and indicate if changes were made. The Creative Commons Public Domain Dedication waiver (http://creativecommons.org/publicdomain/zero/1.0/) applies to the data made available in this article, unless otherwise stated. 
(Continued from previous page)

Conclusions: Malnutrition is prevalent in these settings, which could be partly due to low nutrient intakes, and to socioeconomic factors (including poverty), thus requiring comprehensive approaches that include increased accessibility and affordability of nutrient-dense foods. This study indicates that differences among low-income areas may need consideration for prioritisation and design of interventions.

Keywords: Gender, Socioeconomic status, Malnutrition, Informal settlements

Abbreviations: BMI, Body mass index; Ca, Calcium; DHS, Demographic and health survey; EAR, Estimated average requirement; FAO, Food and Agriculture Organization of the United Nations; FCT, Food composition tables; Fe, Iron; GPS, Global positioning system; HAZ, Height/length-for-age Z-scores; Hb, Haemoglobin; ILRI, International Livestock Research Institute; IMAPP, Intake monitoring, assessment and planning programme; KEMRI, Kenya Medical Research Institute; KES, Kenyan schillings; SD, Standard deviation; TLH, Total livestock holding; TLU, Tropical livestock units; UL, Upper intake level; WDDS, Women dietary diversity score; WHO, World Health Organization; WHZ, Weight-forheight Z-scores; Zn, Zinc

\section{Background}

Although the proportion of underweight children globally decreased from 28 to $17 \%$ between 1990 and 2013 [1], progress has been uneven among countries. In subSaharan Africa, more than half of the countries were seriously or moderately off target for achieving the Millennium Development Goal on underweight reduction at the end of 2015 [2]; thus nutrition remains a priority within the Post-2015 Sustainable Development Goals [3]. Malnutrition levels in sub-Saharan Africa are high and the prevalence of stunting is highest in the East Africa sub-region where $42 \%$ of children are stunted [4]. Such high rates of stunting are a concern since undernutrition in early life can have long-term consequences on health and cognitive development, which in turn have impact on the physical, intellectual and social capacity of the individual and society as a whole [4]. The causes of malnutrition are fairly well understood [5] and effective nutrition-specific interventions have been identified [6]. However, the results achieved by these interventions depend on (unaddressed) structural factors such as education, sanitation, health, or the food environment [4, 7], emphasising the need to understand the multiple pathways to adequate nutrition in different settings. Further, the investigation of indirect predictors and gender disaggregation of data can also help improve our understanding of how to tackle undernutrition in a given context.

In Kenya, the dwellers of Nairobi informal settlements (also known as 'slums' [8]), which are defined as urban areas heavily populated and "characterised by substandard housing and squalor" [9], often have very poor health indicators, including a high prevalence of stunting compared with nationwide estimates [10]. According to the 2014 Demographic and Health Survey (DHS), $26.0 \%$ of children under 5 were stunted nationwide [11] whereas above $40 \%$ were stunted according to surveys in poor settlements in Nairobi between 2008 and 2010 [12-14]. Since $60 \%$ of Nairobi's population lives in informal settlements [9] and these urban settlements are expanding rapidly [15], these high levels of stunting ( $>40 \%)$ represent a serious public health issue. Underlying factors for these stunting rates may be: i) direct factors relating to food security and safety, and infant feeding practices [16, 17], diseases [18], and inadequate water supply and sanitation [19]; and, ii) indirect factors such as socioeconomic status, and women's participation in household decision-making [20]. Maternal social characteristics can influence child-care practices and result in reduced stunting in poor settings [4]. For example, in Korogocho and Viwandani, two Nairobi informal settlements, maternal education, marital status or health seeking behaviour were associated with breastfeeding and complementary feeding practices [17] and with stunting [12]. A better understanding of the social factors associated with nutrition in these fast growing urban populations is necessary to effectively reduce malnutrition.

The role of women (both consumers and providers of care and nutrition in the household) as agents of change is complex. Priorities on food and non-food resource allocation often differ between women and men, and women's empowerment is likely to improve the household's wellbeing [21]. Maternal decision-making capacity and empowerment are needed to use nutrition information effectively and improve child nutrition and care practices [21, 22]. Increasing women's control over assets can also contribute positively to child nutrition [23]. Specifically, the control of animal assets (livestock) is relevant because they can have a positive impact in nutrition, by increasing availability of nutrient-rich animal-source foods, consumed in limited amounts among urban poor consumers [24], or as a source of income [25]. Yet, to tackle undernutrition, context-specific differences in the benefits of gender-equality specific mechanisms and livestock ownership may need to be ascertained.

In this study, a survey was conducted in two lowincome areas of Nairobi, Korogocho and deprived areas 
of Dagoretti. The overall aim was to develop and test a framework to study, in poor urban environments, the associations among consumers' access to and use of different animal-source foods and livestock value chains, and maternal and child nutrition. This paper presents a description of socioeconomic status of the populations living in these areas, particularly related to livestock ownership and gender indicators, and their associations with nutritional outcomes in women and children. This study also provides updated baseline data and new dietary intake data to inform the design of further research, to develop and evaluate strategies aiming to address malnutrition in informal settlements.

\section{Methods}

\section{Study population}

The study was conducted in two low-income areas of Nairobi county: Korogocho, located in Kasarani subcounty and officially classified as an informal settlement, and 5 locations in Dagoretti (now divided into two subcounties, Dagoretti North and South), namely Kawangware, Ruthimitu/Uthiru, Waithaka, Mutuini and Riruta. Higher-income areas in the east of Dagoretti were excluded from the survey. The location of the study areas is shown in Fig. 1. Although they have relatively stable populations, both areas receive migrant populations from all regions in the country. Korogocho is densely populated with 63,318 inhabitants per square km [17], while Dagoretti population density is lower, varying substantially among areas (with a maximum density in Kawangware, with 30,411 inhabitants per square $\mathrm{km} \mathrm{[26]).} \mathrm{The} \mathrm{study}$ areas were selected purposely by the study team based on previous studies showing they had high rates of malnutrition (Korogocho [12]) and high density of livestock (Dagoretti [27]). Most houses in these locations are tinroofed structures, with limited access to piped water, sanitation and electricity $[10,28]$.

\section{Study design}

A cross-sectional survey was conducted between December 2013 and February 2014 in 205 low-income households. The time period overlapped with the end of the short rainy season (November and December). This sample size allowed estimation of at least $10 \%$ prevalence of a condition to within $\pm 5 \%$ (95\% confidence interval) and assuming a design effect of 1.5. A sampling strategy stratified by area was used, in which Global Positioning System (GPS) points were randomly selected in each of the two areas. Once the GPS point was identified, the closest household to the right when facing north was selected. If the first

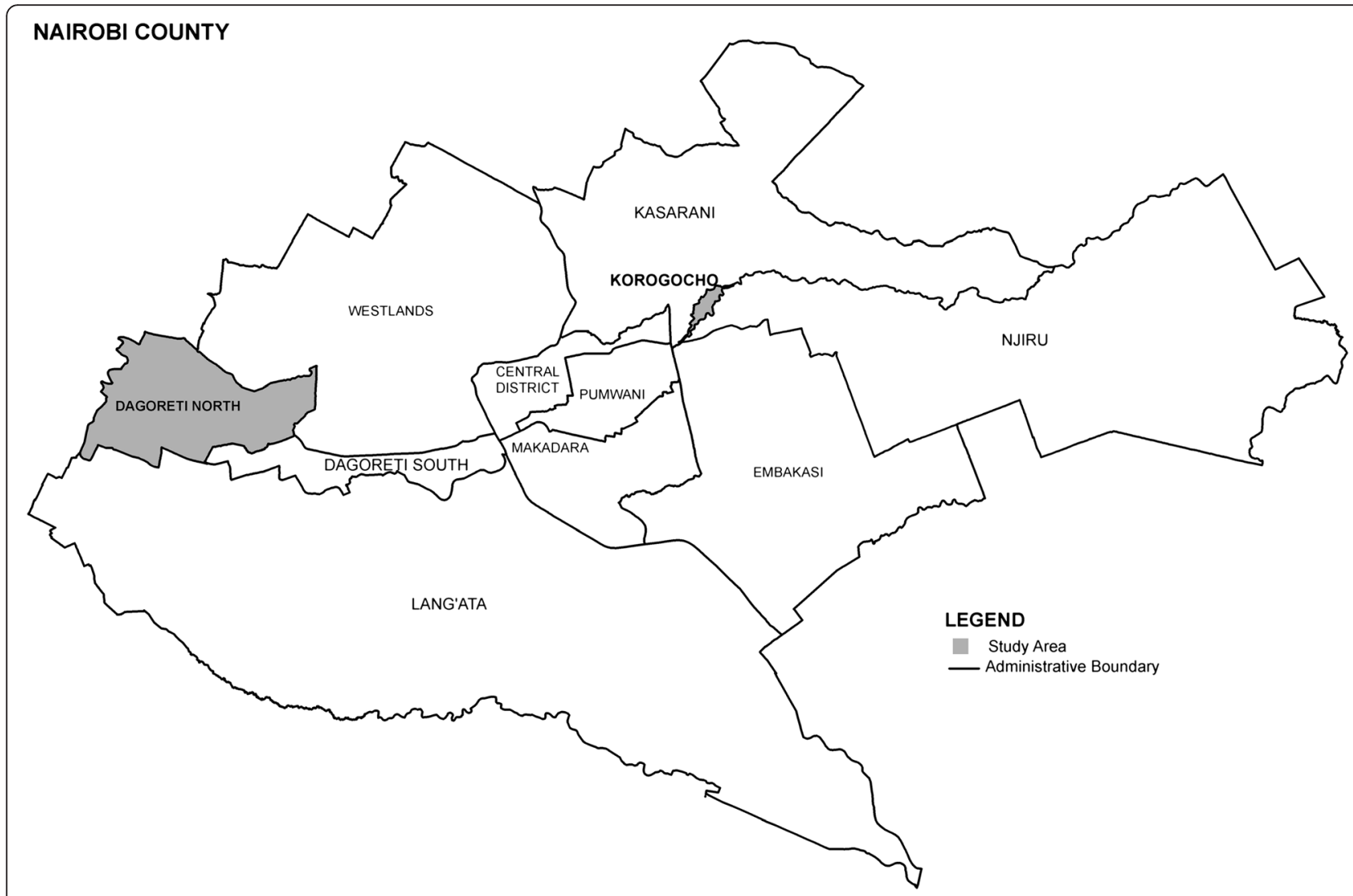

Fig. 1 Map of the study areas within Nairobi County 
household was not eligible, then the next one on the right was selected. Eligibility criteria were: informal housing (temporary) structures; households with low monthly income (below 20,000 Kenyan Schillings (KES), i.e. \$US230) according to estimated incomes for manual workers); presence of at least one child between 1-3 years of age; and, a non-pregnant woman of reproductive age (15-45 years). However, none of households visited with informal housing was found to have an annual income $>20,000$ KES.

\section{Data collection \\ Questionnaire}

Socioeconomic, demographic and health data were collected by means of a structured questionnaire administered by trained interviewers in Swahili. The questions were developed based on ILRI's 'Gender, livestock and livelihoods indicators guidelines' [29] and included details on household structure, housing characteristics, decisionmaking and gender dynamics, ownership of land, and household assets (domestic and animal). Questions on infant feeding practices (e.g. breastfeeding) and health (e.g. vaccines, iron supplementation) were also included. The responses were captured electronically in Android tablets with the open-source tool Open Data Kit (ODK Collect).

\section{Dietary assessment}

The dietary intakes of women and children were assessed using a four-pass 24-h recall [30]. Data were collected on a staggered schedule to avoid a day of the week bias, with an interruption during Christmas and New Year festivities to avoid a bias associated with festive food intakes. Portion sizes (served and left-overs) were estimated using food models, which were weighed (kitchen scale Salter 1036 Slim; precision \pm 1 g) and recorded. Conversion factors were developed to convert the weight of the food models into the weights of food consumed [30]. For some foods, portion sizes were estimated using Kenyan-specific photo books developed by the Kenya Medical Research Institute (KEMRI). For composite cooked dishes, participants were asked for information on the quantity of each ingredient used in the recipe. For these cooked dishes, standard recipes were prepared locally to: i) establish the conversion factors to convert the weight of the food models used to estimate the total recipe weight and the portion of the dish eaten by participants; and ii) estimate standard ingredient proportions to use when the recipe composition could not be obtained directly from the participant. Averaged conversion factors across cooks for the same dish were used.

\section{Anthropometric and biochemical assessment}

Duplicate measurements were made by trained anthropometrists. Recumbent length (children 12-24 months of age) was measured to the nearest $1.0 \mathrm{~cm}$ with a UNICEF wooden baby/infant length/height board and height (mothers and children $>24$ months of age) was similarly measured with a Seca 213 portable stadiometer and the UNICEF wooden board respectively. Maternal and child weight was measured to the nearest $0.1 \mathrm{~kg}$ with a Seca 877 weight scale. Maternal and child haemoglobin levels were measured from finger prick blood samples with an HemoCue 201+ B-Haemoglobin analyser, using standardised procedures.

\section{Data analysis}

A 'gender disparity score' was calculated as the proportion of female members (total number of female family members divided by the total number of family members). Adults were defined as an individual above 16 years of age. Data on asset ownership were used to calculate a 'household domestic asset index', where each of the assets was assigned a weight according to ILRI's 'Gender, livestock and livelihoods indicators guidelines' [29], adapted from an analysis recommended by the Bill and Melinda Gates Foundation for development projects [29]. To calculate this index, non-animal assets (household assets such as cookers/stoves, refrigerators, radios, televisions, mobile phones and mosquito nets; and transport assets such as motorcycles, bicycles and carts) were also assigned a weight according to their depreciation value. A 'gender asset disparity ratio' (Women Domestic Asset Index/ Men Domestic Asset Index) and a 'livestock contribution to the household asset base' (Livestock Asset index / Household Asset Index $x$ 100) were also calculated from the data [29]. In femaleheaded households without males, a value of 1 was given. A score on 'quality of housing' was calculated, adapted from CASHPOR House index used by the Grameen Bank. This score merges housing conditions such as roof and wall building materials, ownership of the housing and number of rooms, as a proxy for poverty [29]. The Total Livestock Holding (TLH) was calculated for each household, by weighting the number of heads of livestock by a speciesand age-specific exchange ratio, and expressed in Tropical Livestock Units (TLU). This index describes livestock biomass across species with a single indicator and summarises the total amount of livestock present at a household [29].

The dietary data were entered in the 'Census and Survey Processing System' to convert food model weights to grams of food consumed and calculate individual energy and nutrient intakes. (CSPro https://www.census.gov/population/ international/software). A food composition table (FCT) compiled for a previous survey in Kenya was used [31]. For foods not available in this database, composition values were obtained from the HarvestPlus FCT for Uganda [32] or from the closest food in the Kenyan FCT. The nutrients assessed were: energy, protein, fat, carbohydrates, calcium $(\mathrm{Ca})$, iron $(\mathrm{Fe})$, zinc $(\mathrm{Zn})$, vitamin $\mathrm{A}$, thiamine $(\mathrm{B} 1)$, riboflavin 
(B2), niacin (B3), vitamin B6, folate, vitamin B12, and vitamin C. Since breastmilk intakes could not be estimated, children were stratified into a breastfeeding and a non-breastfeeding group to estimate dietary adequacy. The percentage of women and non-breastfeeding children "at risk" of inadequate nutrient intakes, was determined using the Estimated Average Requirement (EAR) fixed cut-off approach for all nutrients except iron; and the full probability approach for iron. These analyses were done with the software IMAPP (World Health Organisation (WHO) Intake Monitoring, Assessment and Planning Programme, http://www.side. stat.iastate.edu/imapp.php); and the internal variance ratios based on 2002/2003 NHANES data were used. For breastfed children the WHO recommended nutrient densities of complementary foods were used to identify nutrients that may be low in their diets [33]. In addition dietary diversity scores were estimated to assess dietary quality using the Women Dietary Diversity Score (WDDS), according to Food and Agriculture Organization of the United Nations (FAO) guidelines, [34]; and the WHO Child Minimum Dietary Diversity Score [35]. The percentage of children consuming $\geq 4$ food groups was calculated.

Z-scores for height- or length-for-age (HAZ) and weight-for-height (WHZ), for children, were calculated using WHO 2006 growth standards [36]. Stunting and wasting were defined as a $\mathrm{HAZ}<-2 \mathrm{SD}$ and a $\mathrm{WHZ}<$ $-2 \mathrm{SD}$, respectively, and severe conditions below $-3 \mathrm{SD}$. For women, Body Mass Index (BMI) was calculated as weight $(\mathrm{kg}) /$ height $^{2}\left(\mathrm{~m}^{2}\right)$, and classified according to the International classification [37], in which values under $18.5 \mathrm{~kg} / \mathrm{m}^{2}$ denote underweight and above $25 \mathrm{~kg} / \mathrm{m}^{2} \mathrm{de}-$ note overweight (or obesity for values above $30 \mathrm{~kg} / \mathrm{m}^{2}$ ). Anaemia was defined using the WHO classification: i.e., a cut-off for haemoglobin of $<11 \mathrm{~g} / \mathrm{dL}$ was used for children and $<12 \mathrm{~g} / \mathrm{dL}$ for women [38].

\section{Statistical analysis}

Stata 11.0 was used for the statistical analysis. The distributions of all variables were visually examined and mathematical transformations were done to normalise any non-normal distribution before any analyses were done.

\section{Descriptive statistics}

Means and standard deviation or medians and interquartile ranges were calculated, for normally and nonnormally distributed continuous variables, respectively. Inter-group comparisons were done using Chi-square test and $t$-test for categorical and continuous variables respectively, and Wilcoxon-Mann-Whitney test was used for nonnormally distributed variables.

\section{Unconditional associations}

A subset of data elements collected was chosen for consideration as predictors of the outcomes of interest, based on their biological plausibility, existing literature, the study's aim to evaluate factors associated with female empowerment and animal ownership and the completeness of the data. The analysis of associations between socioeconomic predictors and the main health and growth outcomes was guided by the causal diagram in Fig. 2. Outcomes included three measurements made on the selected child (height-for-age-Z-scores, weight-forheight-Z-scores, and haemoglobin $(\mathrm{Hb})$ level) as well as two maternal measurements (BMI and $\mathrm{Hb}$ ). The normality of each of these outcomes was evaluated graphically and, when non-normality was observed, a variety of transformations considered with the transformation that did the best job of normalizing the distribution being selected. For all continuous predictors, the linearity of the association with each outcome of interest was evaluated using a lowess plot with a quadratic term being created

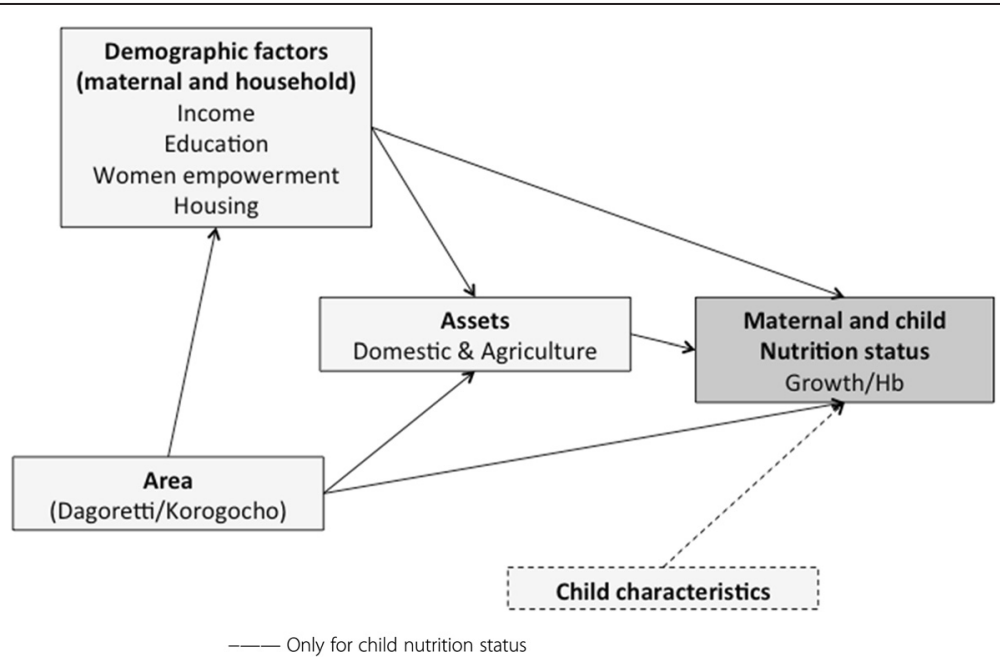

Fig. 2 Causal diagram to investigate socioeconomic predictors of malnutrition 
if there was evidence of curvature in the relationship. The quadratic term was only retained if it showed statistical significance in the unconditional (univariable) models of association. Categorical predictors with small numbers of observations in some categories were recoded to produce the variables used in the analyses (as shown in Table 3). Unconditional associations were assessed for each predictor using simple linear regression models. Variables significant at $P<0.15$ were retained for evaluation in multivariable models.

\section{Multivariable models}

In the multivariable models, two confounders (area and maternal age) were considered to be potentially important and were included into all models. Other variables selected from the unconditional models were assessed in a manual backwards elimination with variables being retained if they were significant at $P<0.1$ or if they appeared to have an important confounding effect. Final models were evaluated through the use of normal probability plots of standardised residuals, scatter plots of residuals vs. predicted values and examining individual records with standardised residuals below -3 or above +3 .

\section{Results}

Descriptive statistics of socioeconomic variables (including a comparison of informal settlements) are presented in Table 1. Descriptive statistics for growth and nutrition parameters are presented in Table 2. Unconditional associations of selected variables are presented in Table 3, and the final multivariable models are presented in Table 4 .

\section{Socioeconomic characterisation Demographics}

Income was below 5,000 KES $(<60 \$)$ per month in over half (53.2 \%) of the households; households in Korogocho had significantly lower incomes than those in Dagoretti ( $p$-value <0.0001) (Table 1). A quarter of the households $(24.9 \%)$ were female-headed, with no significant differences between areas; however, female-headed households had significantly lower incomes than maleheaded household ( $p$-value $=0.006$ ) (differences in socioeconomic characteristics by sex of head of household are shown in the Additional file 1: Table S1). The majority of mothers were married (78.1\%); although there was a significantly higher number of single or widowed mothers $(p$-value $=0.03)$ in Korogocho than in Dagoretti. The women generally had either primary education $(63.9 \%)$ or secondary and above $(34.2 \%)$; few women had not attended school (2.0\%). The women in Dagoretti had a higher level of education than in Korogocho

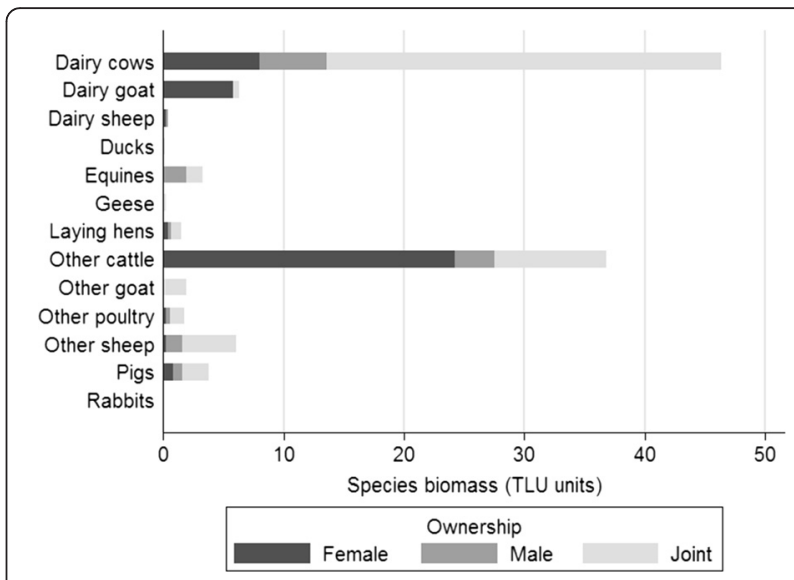

Fig. 3 Total biomass contributed by each of the different species, according to gender of ownership. The Tropical Livestock Units (TLUs) are a common unit to describe livestock numbers across species, through an 'Exchange Ratio' whereby different species of different average size can be compared. The TLUs were calculated according to: 1.1 =camel; $1=$ oxen, bull; $0.8=$ local cow, horses; 0.6 = immature male calves; 0.5 = heifers, donkeys, mules; 0.2 = calves; 0.1 = sheep, goats; $0.01=$ poultry

( $p$-value $<0.001)$. Overall $43.0 \%$ of women in the households had some kind of paid employment, and this proportion was significantly higher in Korogocho than in Dagoretti. Also, all households had at least one person generating some type of income: in $36.3 \%$ of the households it was a male only, in $10.5 \%$ it was a female only, and in the reminder of the households there were at least two people contributing to household income, with $39.5 \%$ of the cases being one male and one female together. In $53.5 \%$ of households, decision-making on income expenditure was reported to be made jointly by male and female adults $(87.0 \%$ of these households were male-headed), while in $22.8 \%$ of households a female made the decisions (26.1\% of these households were male-headed) and in $21.3 \%$ it was a male. Decisions on the use of money were taken independently by the woman and the man in $2.5 \%$ of the households. Higher level of education of the head of household was associated with higher income $(p$-value $=0.015)$ and with type of occupation ( $p$-value $=0.001)$. The dwellings had an average number of rooms of $1.5(\mathrm{SD}=0.9$ rooms, $\mathrm{min} .=$ 1 , $\max .=5)$, which varied by area $(p$-value $=0.028)$, income $(p$-value $=0.003)$ and number of family members ( $p$-value $<0.001)$. The average number of members per household was $4.8(\mathrm{SD}=1.9$, $\min .=2, \max .=13)$, with $2.5(\mathrm{SD}=1.4$, $\min .=1, \max .=7)$ children under 16 years of age.

\section{Assets}

The roofs of all households were made of iron sheets. Walls made from iron sheets were more frequent in Dagoretti than Korogocho $(p$-value $<0.0001)$ and in 
Table 1 Socioeconomic characteristics of participant households, by area

\begin{tabular}{|c|c|c|c|}
\hline & Dagoretti $(n=100)$ & Korogocho $(n=105)$ & N \\
\hline \multicolumn{4}{|l|}{ Income [\%] } \\
\hline Less than 1,000 KES $(<11.5 \$)$ & 3.0 & $9.5^{* * *}$ & \\
\hline $1,001-5,000$ KES (11.5-58\$) & 33.0 & 60.0 & 205 \\
\hline 5,001-10,000 KES (58-116\$) & 40.0 & 25.7 & \\
\hline 10,001-20,000 KES (116-231.5\$) & 24.0 & 4.8 & \\
\hline \multicolumn{4}{|l|}{ Income expenditure decision [\%] } \\
\hline Household male & 18.6 & 23.8 & \\
\hline Household female & 18.6 & 26.7 & 202 \\
\hline Joint (male and female) & 62.8 & 49.5 & \\
\hline \multicolumn{4}{|l|}{ Female contribution to income [\%] } \\
\hline 0 female & 30.7 & 42.9 & 193 \\
\hline 1 female & 58.0 & 44.8 & \\
\hline 2-3 female & 11.3 & 12.3 & \\
\hline \multicolumn{4}{|l|}{ HH head sex [\%] } \\
\hline Female & 43.1 & 56.8 & 205 \\
\hline HH head age [Mean (SD)] & $34.2(9.1)$ & $30.9(9.0)^{*}$ & 184 \\
\hline \multicolumn{4}{|l|}{ HH head religion [\%] } \\
\hline Christian & 98.0 & 92.4 & 205 \\
\hline Muslim & 2.0 & 7.6 & \\
\hline \multicolumn{4}{|l|}{ HH head education [\%] } \\
\hline Never went to school & 2.5 & $1.3^{*}$ & \\
\hline Primary school & 42.5 & 61.5 & 160 \\
\hline Secondary school & 41.3 & 34.6 & \\
\hline College & 13.8 & 2.6 & \\
\hline \multicolumn{4}{|l|}{ HH head occupation [\%] } \\
\hline Unemployed & 2.4 & $0.0^{* *}$ & \\
\hline Farm related & 5.9 & 1.2 & \\
\hline Labourer & 38.8 & 65.9 & 167 \\
\hline Private enterprise & 29.4 & 14.6 & \\
\hline Civil servant & 8.2 & 1.2 & \\
\hline Own business & 15.3 & 17.1 & \\
\hline \multicolumn{4}{|l|}{ Maternal status [\%] } \\
\hline Married & 85.0 & $71.4^{*}$ & 205 \\
\hline Single & 10.0 & 21.9 & \\
\hline Widowed/Divorced/Separated & 5.0 & 6.7 & \\
\hline \multicolumn{4}{|l|}{ Maternal education [\%] } \\
\hline None & 3.0 & $1.0^{* * *}$ & 205 \\
\hline Primary & 49.0 & 78.1 & \\
\hline Secondary and above & 48.0 & 21.0 & \\
\hline \multicolumn{4}{|l|}{ Maternal occupation [\%] } \\
\hline No & 63.0 & $51.4^{*}$ & 205 \\
\hline Yes & 37.0 & 48.6 & \\
\hline \# HH members [Mean (SD)] & $4.7(1.9)$ & $4.9(2.0)$ & 199 \\
\hline Proportion of female members (\#females/\#members) [Mean (SD)] & $0.5(0.2)$ & $0.5(0.2)$ & 199 \\
\hline
\end{tabular}


Table 1 Socioeconomic characteristics of participant households, by area (Continued)

\begin{tabular}{|c|c|c|c|}
\hline & Dagoretti $(n=100)$ & Korogocho $(n=105)$ & $\mathrm{N}$ \\
\hline \# HH children (<15y) [Mean (SD)] & $2.3(1.4)$ & $2.6(1.5)$ & 200 \\
\hline \multicolumn{4}{|l|}{ Land ownership [\%] } \\
\hline No land & 52.6 & $91.3^{* * *}$ & \multirow[t]{3}{*}{200} \\
\hline $0-5000 \mathrm{~m}^{2}$ & 28.9 & 3.9 & \\
\hline$>5000 \mathrm{~m}^{2}$ & 18.5 & 3.9 & \\
\hline \multicolumn{4}{|l|}{ Land usage [\%] } \\
\hline No land & 89.6 & 96.2 & \multirow[t]{3}{*}{200} \\
\hline $0-5000 \mathrm{~m}^{2}$ & 2.1 & 2.9 & \\
\hline$>5000 \mathrm{~m}^{2}$ & 8.3 & 1.0 & \\
\hline Home owned [\%] & 17.0 & 12.4 & 205 \\
\hline \multicolumn{4}{|l|}{ \# rooms [\%] } \\
\hline 1 room & 60.0 & $76.7^{*}$ & \multirow[t]{3}{*}{202} \\
\hline $2-3$ rooms & 32.3 & 21.4 & \\
\hline$>3$ rooms & 7.1 & 1.9 & \\
\hline \multicolumn{4}{|l|}{ Walls material [\%] } \\
\hline Iron sheets & 100.0 & $63.8^{* * *}$ & \multirow[t]{2}{*}{205} \\
\hline Earth/mud & 0.0 & 36.2 & \\
\hline \multicolumn{4}{|l|}{ Quality of housing score [\%] } \\
\hline Poor (0-10) & 82.8 & $80.3^{* * *}$ & \multirow[t]{3}{*}{202} \\
\hline Moderate (11-20) & 17.2 & 9.7 & \\
\hline Good (21-30) & 0 & 0 & \\
\hline \multicolumn{4}{|l|}{ Domestic asset index [\%] } \\
\hline $0-25$ & 70.0 & $97.2^{* * *}$ & \\
\hline $25-50$ & 15.0 & 1.0 & \multirow[t]{4}{*}{205} \\
\hline $50-75$ & 10.0 & 0.0 & \\
\hline $75-100$ & 4.0 & 1.0 & \\
\hline$>100$ & 1.0 & 1.0 & \\
\hline Men domestic asset index $\left[\mathrm{Md}\left(\mathrm{Q}_{1}-\mathrm{Q}_{3}\right)\right]$ & $5.0(2.9-24.3)$ & $2.9(0.8-5.0)^{* * *}$ & 205 \\
\hline Women domestic asset index $\left[\mathrm{Md}\left(\mathrm{Q}_{1}-\mathrm{Q}_{3}\right)\right]$ & $5.7(3.0-20.4)$ & $3.4(2.0-5.8)^{* * *}$ & 205 \\
\hline Gender asset disparity $\left[M d\left(Q_{1}-Q_{3}\right)\right]$ (women/total domestic asset index) & $0.8(0.5-0.9)$ & $0.7(0.5-1.0)$ & 204 \\
\hline Animal ownership $[\%]^{a}$ & 53.0 & $22.9^{* * *}$ & 205 \\
\hline Livestock contribution to $\mathrm{HH}$ asset $\left[\mathrm{Md}\left(\mathrm{Q}_{1}-\mathrm{Q}_{3}\right)\right]$ (livestock/total assets) & $0.0(0.0-0.7)$ & $0.0(0.0-0.0)^{* * *}$ & 204 \\
\hline Livestock contribution to women asset $\left[\mathrm{Md}\left(\mathrm{Q}_{1}-\mathrm{Q}_{3}\right)\right]$ (women livestock/total female assets) & $0.0(0.0-0.8)$ & $0.0(0.0-0.0)^{* * *}$ & 196 \\
\hline \multicolumn{4}{|l|}{ Total livestock holding $[\%]^{\mathrm{b}}$} \\
\hline 0 TLU equivalents & 54.0 & $87.6^{* * *}$ & \\
\hline $0.1-2$ TLU equivalents & 32.0 & 10.5 & \multirow[t]{3}{*}{205} \\
\hline 2.1-4 TLU equivalents & 13.0 & 1.0 & \\
\hline$>4$ TLU equivalents & 1.0 & 1.0 & \\
\hline \multicolumn{4}{|l|}{ Female livestock holding $[\%]^{b}$} \\
\hline 0 TLU equivalents & 63.0 & 90.5 & \multirow[t]{2}{*}{205} \\
\hline$>0$ TLU equivalents & 37.0 & 9.52 & \\
\hline
\end{tabular}

The data were collected between 02-20/12/13 and 7-16/01/14 in Dagoretti, and between 21/01/14 and 21/02/14 in Korogocho

$H H$ household, KES Kenyan schillings, $M d$ median, $n$ sample size, $\mathrm{Q}_{1}$ quartile $25 \%, \mathrm{Q}_{3}$ quartile $75 \%$, SD standard deviation, $T L U$ tropical livestock unit

${ }^{*} p$-value $\leq 0.05 ;{ }^{* *} p$-value $\leq 0.01 ;{ }^{* * *} p$-value $\leq 0.001$

${ }^{\mathrm{a}}$ This includes both livestock and non-livestock animals; ${ }^{\mathrm{b}}$ The TLUs are calculated according to: $1.1=$ camel; $1=$ oxen, bull; $0.8=$ local cow, horses; $0.6=$ immature

male calves; 0.5 = heifers, donkeys, mules; 0.2 = calves; $0.1=$ sheep, goats; 0.01 = poultry 
Table 2 Nutritional indicators of participant children and women in poor households of Nairobi, by area

\begin{tabular}{|c|c|c|c|c|c|c|c|c|c|c|}
\hline & \multicolumn{7}{|c|}{ CHILDREN 1-3 YEARS } & \multicolumn{3}{|c|}{ WOMEN REPRODUCTIVE AGE } \\
\hline & \multicolumn{4}{|c|}{ BREASTFEEDING } & \multicolumn{3}{|c|}{ Non-BREASTFEEDING } & \multicolumn{3}{|c|}{ NON-PREGNANT } \\
\hline & Dagoretti $(n=35)$ & \multicolumn{3}{|c|}{ Korogocho $(n=42)$} & Dagoretti $(n=65)$ & \multicolumn{2}{|c|}{ Korogocho $(n=62)$} & Dagoretti $(n=100)$ & \multicolumn{2}{|c|}{ Korogocho $(n=104)$} \\
\hline $\begin{array}{l}\text { Age [months//years] } \\
\text { [Mean (SD)] }\end{array}$ & $17.8(4.0)$ & \multicolumn{2}{|l|}{$18.5(5.2)$} & & $25.4(5.9)$ & \multicolumn{2}{|l|}{$25.9(7.1)$} & $26.7(6.3)$ & \multicolumn{2}{|l|}{$25.6(5.9)$} \\
\hline Child female [\%(Cl)] & $48.6(31.5-65.6)$ & \multicolumn{2}{|c|}{$34.9(20.2-49.5)$} & & $44.6(32.3-56.9)$ & \multicolumn{2}{|l|}{$45.2(32.6-57.8)$} & - & \multicolumn{2}{|l|}{-} \\
\hline Child prematurity [\%(Cl)] & $11.4(0.6-22.3)$ & \multicolumn{2}{|c|}{$11.6(1.8-21.5)$} & & $4.7(-0.6-10.0)$ & \multicolumn{2}{|l|}{$8.2(1.2-15.2)$} & - & \multicolumn{2}{|l|}{-} \\
\hline $\begin{array}{l}\text { HAZ [Z-scores] } \\
\text { [Mean (SD)] }\end{array}$ & $-1.34(1.07)$ & \multicolumn{2}{|c|}{$-2.23^{* * *}(0.98)$} & & $-1.70(1.27)$ & \multicolumn{2}{|l|}{$-1.90(1.17)$} & - & \multicolumn{2}{|l|}{-} \\
\hline $\begin{array}{l}\text { WHZ [Z-scores] } \\
\text { [Mean (SD)] }\end{array}$ & $-0.15(1.34)$ & \multicolumn{2}{|l|}{$-0.45(1.17)$} & & $0.07(1.46)$ & \multicolumn{2}{|l|}{$-0.14(1.09)$} & - & \multicolumn{2}{|l|}{-} \\
\hline BMI [kg/m²] [Mean (SD)] & - & \multicolumn{2}{|l|}{-} & & - & \multicolumn{2}{|l|}{-} & $24.2(4.6)$ & \multicolumn{2}{|l|}{$23.3(3.8)$} \\
\hline $\begin{array}{l}\text { Haemoglobin }[\mathrm{g} / \mathrm{dL}] \\
\text { [Mean (SD)] }\end{array}$ & $10.1(1.1)$ & \multicolumn{2}{|l|}{$10.2(1.3)$} & & $10.2(1.3)$ & \multicolumn{2}{|l|}{$9.8(1.7)$} & $12.7(1.8)$ & \multicolumn{2}{|l|}{$12.8(1.8)$} \\
\hline $\begin{array}{l}\text { Prevalence of: }[\%(C I)] \\
\text { Stunting (<-2Z-score) }\end{array}$ & $25.7(10.5-40.9)$ & \multicolumn{2}{|c|}{$53.5^{*}(38.0-69.0)$} & & $38.5(26.3-50.6)$ & $45.2(32.4-57.9)$ & & & & \\
\hline Wasting (<-2Z-score) & $2.9(-0.3-8.7)$ & $11.6(1.6-21$. & & & $1.5(-0.2-4.6)$ & $3.2(-0.1-7.7)$ & & & & \\
\hline $\mathrm{BMI}<18.5 \mathrm{~kg} / \mathrm{m}^{2}$ (underweight) & - & - & & & - & - & & $7.0(1.9-12.1)$ & $9.5(3.8-15.2)$ & \\
\hline BMI $>25$ kg/m² (overweight) & - & - & & & - & - & & $22.2(13.9-30.6)$ & $16.3(9.1-23.6)$ & \\
\hline BMI >30 kg/m² (obese) & - & - & & & - & - & & $12.1(5.6-18.7)$ & $7.7(2.5-12.9)$ & \\
\hline $\begin{array}{l}\text { Anaemia }(<11 \mathrm{~g} / \mathrm{dL}) / / \\
(<12 \mathrm{~g} / \mathrm{dL})[\%(\mathrm{Cl})]\end{array}$ & 85.7 (73.5-97.9) & $65.1(50.3-8$ & $.0)^{*}$ & & $70.8(59.4-82.1)$ & $77.4(66.7-88.1)$ & & $26.0(17.3-34.7)$ & $25.7(17.2-34.2)$ & \\
\hline $\mathrm{MDD}^{\mathrm{a}}[\%(\mathrm{Cl})]$ & 74.3 (59.4-89.2) & $52.4^{*}(36.8-6$ & & & $83.1(73.8-92.4)$ & $61.3^{* *}(48.9-73$ & 3.6) & - & - & \\
\hline WDDS $^{\mathrm{b}}[$ Mean (SD)] & - & - & & & - & - & & $4.4(1.1)$ & $4.1^{*}(1.4)$ & \\
\hline $\begin{array}{l}\text { Intake of: } \\
\text { [Mean (SD)] }\end{array}$ & Complementary fo & ood intake & $\begin{array}{l}\text { WHC } \\
\text { intak }\end{array}$ & $\begin{array}{l}002 \text { recommended } \\
\text { (12-23 months) }\end{array}$ & Total in & ntake & $\begin{array}{l}\text { Total \% at risk } \\
\text { of inadequacy }\end{array}$ & Total in & ntake & $\begin{array}{l}\text { Total\% at risk } \\
\text { of inadequacy }\end{array}$ \\
\hline Energy [kcal/d] & $898.4(572.9)$ & $703.5(399.0)$ & & - & $1255.7(441.2)$ & $1009.9^{* *}(514.5)$ & - & $1928.7(725.5)$ & $1768.1(822.4)$ & - \\
\hline Carbohydrates $[\mathrm{g} / \mathrm{d}]$ & $154.4(104.3)$ & $124.0(69.4)$ & & - & $206.2(75.6)$ & $171.8(86.3)^{*}$ & - & $320.5(119.2)$ & $295.8(137.5)$ & - \\
\hline Protein $[\mathrm{g} / \mathrm{d}]$ & $22.4(15.2)$ & $17.6(11.2)$ & & - & $33.1(14.2)$ & $24.1^{* * *(15.4)}$ & 6.1 & $47.9(22.0)$ & $42.9(25.5)$ & 30.6 \\
\hline Fats $[\mathrm{g} / \mathrm{d}]$ & $22.7(19.3)$ & $17.0(14.1)$ & & - & $35.6(17.6)$ & $27.0^{* *}(19.5)$ & - & $53.1(30.9)$ & $48.5(33.41)$ & - \\
\hline Calcium [mg/d] & $265.8(189.8)$ & $222.4(188.4)$ & & 500 & $481.6(257.3)$ & $343.7^{* *}(242.2)$ & 52.4 & $597.9(328.7)$ & $461.4^{* * *}(299.4)$ & 93.8 \\
\hline Iron [mg/d] & $5.4(4.1)$ & $4.1(2.9)$ & & 5.8 & $7.7(3.9)$ & $5.7^{* *}(4.0)$ & 98.7 & $13.0(7.5)$ & $11.8(7.4)$ & 19.6 \\
\hline Zinc $[\mathrm{mg} / \mathrm{d}]$ & $3.2(1.9)$ & $2.4(1.4)$ & & 4.1 & $4.8(2.4)$ & $3.3^{* * *}(1.9)$ & 7.7 & $7.1(3.1)$ & $6.1^{*}(3.5)$ & 61.3 \\
\hline Vitamin A [ug RE/d] & $676.4(825.0)$ & $495.1(687.2)$ & & 400 & $770.9(675.4)$ & $561.2(629.5)$ & 11.5 & $1575.3(1620.3)$ & $1409.7(1516.9)$ & 6.9 \\
\hline Vitamin B1 $[\mathrm{mg} / \mathrm{d}]$ & $0.5(0.4)$ & $0.4(0.3)$ & & 0.5 & $0.7(0.4)$ & $0.5^{* *}(0.5)$ & 22.6 & $1.1(0.7)$ & $1.0(0.6)$ & 32.3 \\
\hline
\end{tabular}


Table 2 Nutritional indicators of participant children and women in poor households of Nairobi, by area (Continued)

\begin{tabular}{|c|c|c|c|c|c|c|c|c|c|}
\hline \multirow{4}{*}{$\begin{array}{l}\text { Intake of: } \\
\text { [Mean (SD)] } \\
\text { Vitamin B2 [mg/d] }\end{array}$} & \multicolumn{6}{|c|}{ CHILDREN 1-3 YEARS } & \multirow{2}{*}{\multicolumn{3}{|c|}{$\begin{array}{c}\text { WOMEN REPRODUCTIVE AGE } \\
\text { NON-PREGNANT }\end{array}$}} \\
\hline & \multicolumn{3}{|c|}{ BREASTFEEDING } & \multicolumn{3}{|c|}{ Non-BREASTFEEDING } & & & \\
\hline & \multicolumn{2}{|c|}{ Complementary food intake } & $\begin{array}{l}\text { WHO } 2002 \text { recommended } \\
\text { intake }(12-23 \text { months) }\end{array}$ & \multicolumn{2}{|c|}{ Total intake } & $\begin{array}{l}\text { Total } \% \text { at risk } \\
\text { of inadequacy }\end{array}$ & \multicolumn{2}{|c|}{ Total intake } & \multirow{2}{*}{$\begin{array}{c}\text { Total\% at risk } \\
\text { of inadequacy } \\
49.7\end{array}$} \\
\hline & $0.6(0.5)$ & $0.4(0.3)$ & 0.5 & $0.8(0.4)$ & $0.6^{* * *}(0.5)$ & 18.8 & $1.0(0.5)$ & $0.9^{*}(0.5)$ & \\
\hline Vitamin B3 [mg/d] & $5.8(3.8)$ & $4.1(3.9)^{*}$ & 6 & $7.4(3.5)$ & $5.3^{* * *}(3.2)$ & 33.5 & $10.3(4.4)$ & $9.2(5.3)$ & 70.0 \\
\hline Vitamin B6 [mg/d] & $0.9(0.6)$ & $0.7(0.6)$ & 0.5 & $1.2(0.7)$ & $0.8^{* * *}(0.5)$ & 8.9 & $1.5(0.8)$ & $1.3^{*}(0.8)$ & 22.9 \\
\hline Folate [ug DFE/d] & $209.9(232.6)$ & $122.9^{*}(116.7)$ & 160 & $303.4(244.7)$ & $220.1^{*}(206.8)$ & 18.9 & $468.1(411.7)$ & $359.8^{*}(317.5)$ & 33.1 \\
\hline Vitamin B12 [ $\mathrm{\mu g} / \mathrm{d}]$ & $5.2(7.3)$ & $4.8(5.4)$ & 0.9 & $7.4(9.7)$ & $4.8(6.5)$ & 8.8 & $14.9(17.7)$ & 16.9 (17.9) & - \\
\hline Vitamin C [mg/d] & $55.7(44.7)$ & $57.3(55.4)$ & 30 & $80.9(59.5)$ & $70.9(68.7)$ & 3.2 & $131.5(92.8)$ & $123.4(104.6)$ & 6.3 \\
\hline
\end{tabular}

$n$ for child intake $=204 ; n$ for women intake $=204$

The data were collected between 02-20/12/13 and 7-16/01/14 in Dagoretti, and between 21/01/14 and 21/02/14 in Korogocho

$B M I$ body mass index, $C l$ confidence interval, DFE dietary folate equivalents, $H A Z$ height-for-age Z-scores, $n$ sample size, N/A not available, $R E$ retinol equivalents, $R N I$ recommended nutrient intake, SD standard deviation, WHZ weight-for-height Z-scores

${ }^{*} p$-value $\leq 0.05 ;{ }^{* *} p$-value $\leq 0.01 ; * * * p$-value $\leq 0.001$

${ }^{a}$ Minimum Dietary Diversity (MDD) for infants: proportion of children 6-23 months of age who received foods from 4 or more food groups (on a 7-point food group scale proposed by WHO for children 6-23 months, here used up to 36 months) [35]; 'Women's Dietary Diversity Score (WDDS) for women: 9-point food group score proposed by FAO [34]; ${ }^{\mathrm{C}}$ Acording to WHO 2002 intakes [33]; ${ }^{\mathrm{d}}$ Prevalence of inadequacy calculated by IMAPP software, based on EAR cut-off point

// difference in indicator or units for children and women 
higher-income than lower-income households $(p$-value $=$ $0.04)$. The composite quality of housing score was 6.5 on average $(\mathrm{SD}=2.3$, min. $=1$, max. $=7)$ which is considered as 'poor' [29], and there were significant differences by area $(p$-value $<0.001)$ and by household income ( $p$-value $=0.003)$. Most households (94.1\%) had a cooker, but different types of fuels were used: most commonly kerosene/ gas (72.2\%), followed by charcoal/wood (27.3\%), and one household had electricity/battery. Only two households had a refrigerator. The majority of households $(88.8 \%)$ had at least one mobile phone in the household, $66.3 \%$ had at least one mosquito net, $56.1 \%$ had a radio and $48.3 \%$ had a television. Only $9.3 \%$ of the households had a bicycle, $3.4 \%$ a motorbike and $1.5 \%$ a cart.

\section{Livestock}

Livestock were kept by $29.3 \%$ of households (Fig. 3 shows the animal species) and of these, two households had animals that they kept for others. Poultry was the most frequent species kept; local bird breeds were kept by $22.9 \%$ of the households and only one household owned exotic poultry. Cattle were the second most commonly kept livestock (14.6\% of the households). The livestock biomass contributed by different species is shown in Fig. 3, as well as the ownership by gender. The percentage of households owning animals increased with income $(p$-value $=0.001)$ and in Dagoretti was more than double of Korogocho. The total livestock holding was also significantly higher in Dagoretti (mean $=0.67, \mathrm{SD}=1.17)$ compared to Korogocho (mean $=0.28, \mathrm{SD}=2.35)(p$-value $<0.001)$. The livestock contribution to the total household asset base across all households was $18.2 \%$. Of the households reporting they had one or more livestock species, $61.6 \%$ reported to have animals mainly for subsistence, $53.3 \%$ reported to have species which were mainly for selling, $13.3 \%$ had horses, donkeys or cattle for the purpose of draft and other work, and one household reported to have cattle for bull fighting. Also, amongst livestock- keeping households, $62.7 \%$ kept their animals outside the urban area, $33.9 \%$ kept their livestock in structures attached to their household and $3.4 \%$ kept their animals elsewhere within the urban area. The specific livestock contribution to the asset base for women was $52.4 \%$. Animals were mostly said to belong to the household and not to any specific member of the family. When attributed to a specific member, they were more often attributed to female than to male members, although the sample size was too small to test for a true difference.

\section{Maternal and child nutrition Children 1-3 years}

Overall, $8.3 \%$ of the children were reported to be premature at birth. At the time of the survey, $43.4 \%$ of children were still breastfeeding, although only $37.3 \%$ were reported to have consumed breastmilk on the previous day. Of the $55.6 \%$ of children who were not breastfeeding, $99 \%$ were reported to have been breastfed earlier in life, with a mean duration of 17.1 months ( $\mathrm{SD}=5.5$ months). Just over half the children $(54.5 \%)$ were reported to have been exclusively breastfed up to 6 months of age and the introduction of liquids took place on average at 4.1 months ( $\mathrm{SD}=2.4$ months) and of solid food at 5.4 months ( $\mathrm{SD}=1.9$ months), with no statistical differences by gender. A majority of children (82.0 \%) was reported to have taken vitamin A capsules over the previous 6 months. Three of the children had been in a therapeutic feeding programme during the last three months, one of whom was still in the programme; one child had been in a supplementary feeding programme. None of the children was reported to have positive HIV status but only $51.2 \%$ had been tested. It was reported that $22.9 \%$ of children had been sick within the past $24 \mathrm{~h}$, with cough (9.2\%), fever (8.3\%), diarrhoea (5.9\%) or vomiting (2.9\%) as the most common symptoms.

Table 2 summarises the dietary and nutritional indicators of breastfeeding and non-breastfeeding children by area (child sex differences are shown in the Additional file 1: Table S2). Breastfeeding children were significantly younger $(p$-value $<0.0001)$ but did not differ in other nutritional indicators. Total prevalence of acute malnutrition was $4.4 \%$, with $1.0 \%$ severely wasted and no cases of oedema reported; total stunting was $41.5 \%$, with $14.2 \%$ of cases severe stunting. The mean height-for age Z-scores was lower in Korogocho than Dagoretti (0.47 SD lower, $p$ value $=0.004)$ and in boys than girls $(0.38 \mathrm{SD}, p$-value $=$ 0.02). Anaemia was found in $74.1 \%$ of children, with $2.4 \%$ of cases severe anaemia. Among the wasted children $66.7 \%$ were also stunted (the $ß$ coefficient of the linear regression between height-for-weight and height-for-age was $0.164, p$-value $=0.031)$ and $88.9 \%$ were also anaemic (the $§$ coefficient of the linear regression between heightfor-weight and haemoglobin levels was $0.155, p$-value $=$ 0.016). There was no association between height-for-age and haemoglobin levels.

It was reported that $13.2 \%$ of children had lower total dietary intakes than usual on the day prior to the survey. The estimated energy and nutrient intakes, the percentages at risk of inadequate nutrient intakes (non-breastfed children and women only), and the percentage of children with a dietary diversity score $\geq$ four food groups are also shown in Table 2 (differences by sex in Additional file 1: Table S2). The energy and nutrient intake data for breastfeeding children was from complementary foods alone (i.e. not including intakes from breastmilk). Overall, more than a third of non-breastfed children were at risk of inadequate intakes of calcium, iron or niacin (up to $98.7 \%$ in 
the case of iron); whereas the percentage of children at risk of inadequate intakes of zinc and vitamins B6, B12 and $\mathrm{C}$ were low $(<10 \%)$. Just over two thirds of the children (i.e., $68.6 \%$ ) were consuming diets that had the recommended foods from 4 or more food groups, although this percentage was significantly lower in Korogocho than Dagoretti $(80.0 \%$ vs $57.7 \%$, $p$-value $=0.001)$; the difference between boys and girls was not significant. On the 24-h recall day, over $50 \%$ of children consumed foods from the staples (starchy tubers and grains), green leaves, other vegetables (mostly tomato) and dairy products; whereas less than $30 \%$ and $10 \%$ consumed flesh foods and eggs, respectively (Fig. 4). Iron intake was not found to be associated with haemoglobin levels in any of the groups.

\section{Women of reproductive age}

The mean age was 26.2 years ( $\mathrm{SD}=6.1$ years). Night blindness was reported by $6.3 \%$ of women. None of the women were taking iron supplements at the time of the survey, however, $41.0 \%$ reported to have taken iron supplements during their last pregnancy, of whom $86.3 \%$ reported taking them seven days a week over an average length of 4.9 weeks ( $\mathrm{SD}=6.7$ weeks), and $15.2 \%$ of women took iron supplements for 12 weeks or more. Relatively few women reported being HIV-positive (i.e., $6.3 \%$ ).

Not having enough food for the family 'occasionally' (less than 15 times a year) was reported by $28.8 \%$ of women, and 'often' (above 15 times a year) by $29.8 \%$. Women's nutrition and dietary indicators by area are summarised in Table 2 (and by sex of head of household, in the Additional file 1: Table S2). Less than $10 \%$ of women were under-weight $\left(\mathrm{BMI}<18.5 \mathrm{~kg} / \mathrm{m}^{2}\right)$, whereas close to
$30 \%$ were over-weight or obese $\left(\mathrm{BMI}>25 \mathrm{~kg} / \mathrm{m}^{2}\right)$ of which $9.9 \%$ were obese $\left(\mathrm{BMI}>30 \mathrm{~kg} / \mathrm{m}^{2}\right)$. The BMI was not associated with HIV status. The prevalence of anaemia was $25.9 \%$ : $1.5 \%$ of cases were severe, $14.2 \%$ moderate and $10.2 \%$ mild. No differences in nutritional status were detected between areas or depending on the sex of the household head. Lower than normal dietary intakes on the day prior to the survey was reported by $11.2 \%$ of women and $5.4 \%$ had been sick, mostly due to head or other body pain. Over a third of the women were at risk of inadequate intakes of calcium, zinc, riboflavin, niacin and folate (up to $93.8 \%$ in the case of calcium); whereas fewer than $20 \%$ were at risk of inadequate intakes of iron. Dietary iron intakes and reported length of iron supplementation were not associated with haemoglobin levels among these women. The average percentage of contribution to energy intake was slightly low for protein (9.6\% vs recommended 10-35 \%), normal for fat (23.5 \% - recommended 20$35 \%)$ and high for carbohydrates (68.1 \% vs recommended 45-65\%). The women dietary diversity score was 0.2 points lower in Korogocho $(p$-value $=0.04)$ and the food groups consumed are shown in Table 4. As for children, over $50 \%$ of women consumed over the last $24 \mathrm{~h}$ staples, green leaves, other vegetables and dairy products; whereas less than $30 \%$ and $10 \%$ consumed flesh foods and eggs, respectively (Fig. 4).

\section{Predictors of malnutrition}

The direction and statistical significance of the unconditional linear regression models for predictors of interest of nutritional outcomes are shown in Table 3 (the $B$-coefficients are shown in the Additional file 1: Table S3). The $ß$-coefficients of the statistically significant variables
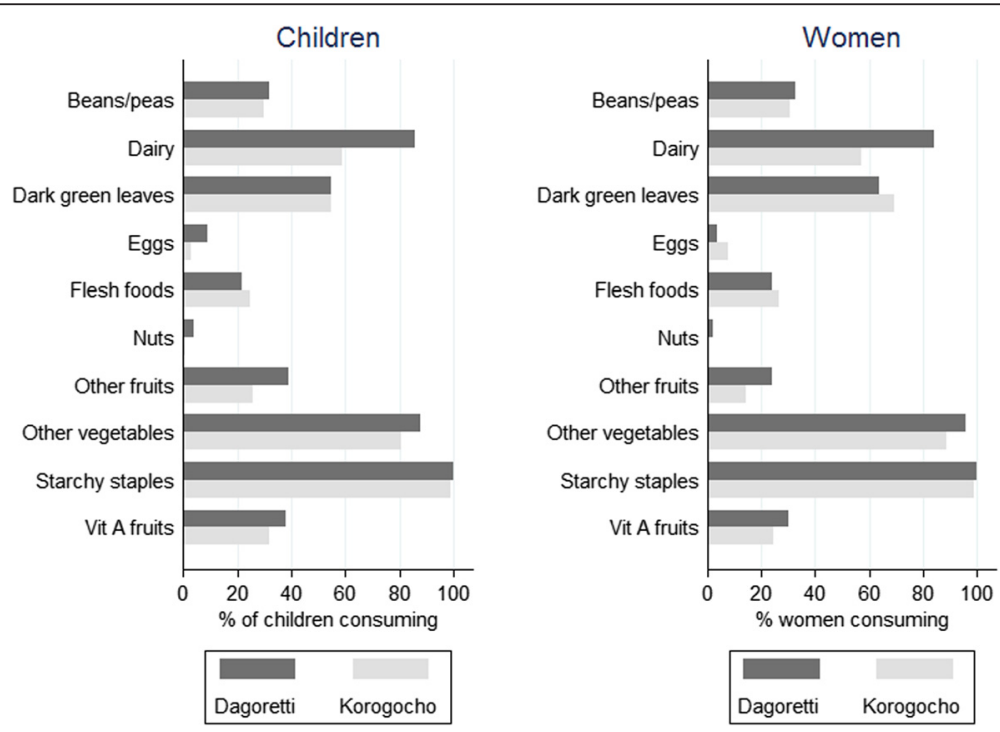

Fig. 4 Food group contribution to the dietary intake of children and women. The food groups are obtained from the 24-h dietary recall of women and children, and based on the food group categories proposed by the Minimum Dietary Diversity for women (MDD-W) 
Table 3 Univariable regression analysis for predictors of interest of nutritional outcomes

\begin{tabular}{|c|c|c|c|c|c|c|c|}
\hline Description & Categories & $\mathrm{n}$ & $\beta \mathrm{HAZ}$ & $\beta \mathrm{WHZ}$ & $\beta \mathrm{Ch} \mathrm{Hb}$ & $\beta \mathrm{MBMI}^{\mathrm{b}}$ & $\beta \mathrm{M} \mathrm{Hb}^{\mathrm{c}}$ \\
\hline Area & $0=$ Dagoretti; $1=$ Korogocho & $100 / 104$ & $-* * *$ & - & - & $-*$ & + \\
\hline \multirow[t]{4}{*}{ Household income } & $1=<1 \mathrm{~K}$ & 12 & Base & Base $^{*}$ & Base $^{* *}$ & Base $e^{* * *}$ & Base \\
\hline & $2=1 \mathrm{~K}-5 \mathrm{~K}$ & 96 & - & - & + & - & + \\
\hline & $3=5 \mathrm{~K}-10 \mathrm{~K}$ & 67 & - & - & - & + & + \\
\hline & $4=10 \mathrm{~K}-20 \mathrm{~K}$ & 29 & + & - & + & + & + \\
\hline \multirow[t]{3}{*}{ Income expenditure decision } & $1=$ Female & 45 & Base & Base & Base & Base & Base \\
\hline & 2= Male & 43 & + & + & & - & + \\
\hline & $3=$ Joint & 113 & - & + & & + & + \\
\hline Female contribution to income & $0=\mathrm{No} ; 1=$ Yes & $72 / 120$ & - & - & - & $+* *$ & + \\
\hline HH head sex & $0=$ Male; $1-=$ Female & $154 / 51$ & + & - & + & - & + \\
\hline HH head education & $0=$ None or $1^{\text {ary }} ; 1=$ Secondary + & $113 / 83$ & $+* * *$ & - & + & - & - \\
\hline Maternal status & $0=$ Not married; $1=$ Married & $44 / 160$ & $-*$ & + & - & - & $-*$ \\
\hline Maternal education & $0=$ None or $1^{\text {ary }} ; 1=$ Secondary + & $134 / 70$ & $+*$ & - & + & + & $-*$ \\
\hline Maternal occupation & $0=$ None, student $; 1=$ All other & $118 / 86$ & - & - & - & + & $+{ }^{*}$ \\
\hline \# HH children $(<15 y)$ & $1=1 ; 2=2 ; 3=>3$ & $54 / 68 / 77$ & - & + & - & + & - \\
\hline Quality of housing score & $0=4-6 ; 1=8-16$ & $163 / 38$ & $+*$ & + & $+*$ & $+* *$ & + \\
\hline Domestic asset index & - & 203 & + & $+*$ & + & $+* *$ & + \\
\hline Women domestic asset index & - & 203 & $+* * *$ & + & + & $+* *$ & + \\
\hline Domestic livestock asset index & - & 203 & - & $+* * *$ & + & $+* *$ & + \\
\hline Women livestock asset index & $0=0 ; 1=>0$ & $158 / 46$ & + & $+* *$ & - & $+* * *$ & $-* *$ \\
\hline Total livestock holding & $0=0 ; 1=>0$ & $145 / 59$ & + & $+*$ & + & $+* *$ & $-*$ \\
\hline Female livestock holding & $0=0 ; 1=>0$ & $157 / 47$ & $+* *$ & $+* *$ & + & $+* * *$ & $-*$ \\
\hline Maternal age [yrs] & - & 204 & quad $^{a}$ & + & + & $+* * *$ & + \\
\hline Child age [months] & - & 204 & $-* *$ & + & $+* *$ & + & + \\
\hline Child sex & $0=$ Male; $1=$ Female & $116 / 88$ & $+* * *$ & - & + & - & - \\
\hline Prematurity & $0=\mathrm{No} ; 1=$ Yes & $186 / 16$ & - & $-* *$ & + & + & $-* *$ \\
\hline
\end{tabular}

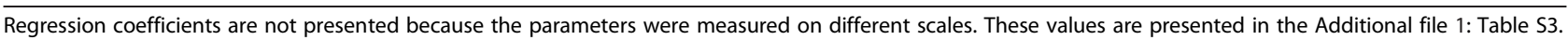
The sign (+/-) indicates the direction of the relationship and the "**"indicated the statistical significance $\left({ }^{*} p\right.$-value $\leq 0.15,{ }^{* *} p$-value $\leq 0.1,{ }^{* * *} p$-value $\leq 0.05 ;$ Ch $=$ child; $\mathrm{HH}=$ household; $\mathrm{M}=$ mother; $n=$ sample size

${ }^{a}$ quadratic function with peak at approximately 30 years

${ }^{b}$ mother's BMI was log transformed to improve normality of distribution

'mother's $\mathrm{Hb}$ was transformed as $(\mathrm{Hb} \wedge 3) / 1000$ to improve normality of distribution

in the multivariable regression analysis are shown in Table 4. The factors significantly associated with nutritional status were: for child height-for-age, living in Dagoretti, being a girl and having a non-married mother were associated with better Z-scores and the household head's education was marginally associated. For weightfor-height, living in Dagoretti and female ownership of livestock were positively associated (marginally in the case of female livestock holding) while income was negatively associated. Regarding maternal nutrition, BMI was positively associated with age and negatively associated with income; whereas hemoglobin levels were marginally associated with prematurity of child at birth.

Finally simple linear regression showed an association between certain nutritional indicators of a child and those of their mothers/caregivers: haemoglobin levels of woman and child had a $ß$-coefficient of 0.152 ( $p$-value $=$ 0.006), child weight-for-height and woman BMI had a $\beta$ coefficient of $0.614(p$-value $=0.014)$, and child heightfor-age and women height had a $ß$-coefficient of 0.030 $(p$-value $=0.032)$.

\section{Discussion}

This paper documents socioeconomic and nutrition characteristics of two areas of informal settlements in Nairobi, Kenya. Even though Dagoretti's deprived areas are urban by definition, they have a peri-urban character, with lower population density and more agriculture activities, than Korogocho, which is a shanty-town inside the city. The levels of malnutrition and risk of inadequate intakes were high, highlighting that pockets of malnutrition exist in poor urban areas of Nairobi. 
Table 4 Multivariable regression analysis for predictors of interest of nutritional outcomes

\begin{tabular}{|c|c|c|c|c|c|c|c|}
\hline Description & Categories & $n$ & $\beta$ HAZ (p-val) & $\beta W H Z$ ( $p$-val) & $\beta \mathrm{Ch} \mathrm{Hb}(p$-val) & $\beta \mathrm{M} \mathrm{BMI}^{\mathrm{a}}(p$-val) & $\beta \mathrm{M} \mathrm{Hb}^{\mathrm{b}}(p$-val) \\
\hline Area & $\begin{array}{l}0=\text { Dagoretti } \\
1=\text { Korogocho }\end{array}$ & $100 / 104$ & $-0.427(0.014)$ & $-0.392(0.045)$ & $-0.239(0.219)$ & $-0.004(0.893)$ & $0.021(0.849)$ \\
\hline \multirow[t]{4}{*}{ Household income } & $1=<1 \mathrm{~K}$ & 12 & & base $(0.009)^{c}$ & & base $(0.019)^{c}$ & \\
\hline & $2=1 \mathrm{~K}-5 \mathrm{~K}$ & 96 & & $-0.140(0.714)$ & & $-0.065(0.226)$ & \\
\hline & $3=5 \mathrm{~K}-10 \mathrm{~K}$ & 67 & & $-0.682(0.087)$ & & $-0.007(0.899)$ & \\
\hline & $4=10 \mathrm{~K}-20 \mathrm{~K}$ & 29 & & $-0.929(0.037)$ & & $0.051(0.409)$ & \\
\hline HH head education & $\begin{array}{l}0=\text { None or } 1^{\text {ary }} \\
1=\text { Secondary }+\end{array}$ & $113 / 83$ & $0.313(0.076)$ & & & & \\
\hline Maternal status & $\begin{array}{l}0=\text { Not married } \\
1=\text { Married }\end{array}$ & $44 / 160$ & $-0.427(0.045)$ & & & & \\
\hline Female livestock holding & $0=0 ; 1=>0$ & $157 / 47$ & & $0.426(0.054)$ & & & \\
\hline Maternal age [yrs] & - & 204 & $0.000(0.973)$ & $0.010(0.479)$ & $0.017(0.299)$ & $0.007(<0.0001)$ & $-0.002(0.833)$ \\
\hline Child age [months] & - & 204 & $-0.021(0.082)$ & & & & \\
\hline Child sex & $\begin{array}{l}0=\text { Male; } \\
1=\text { Female }\end{array}$ & $116 / 88$ & $0.332(0.050)$ & & & & \\
\hline Prematurity & $0=\mathrm{No} ; 1=\mathrm{Yes}$ & $186 / 16$ & & & & & $-0.344(0.098)$ \\
\hline
\end{tabular}

B-coefficients and $p$-values ( $p$-val) are presented. $C h$ child, $H H$, household, $M$ mother, $n$ sample size

amother's BMI was log transformed to improve normality of distribution

${ }^{b}$ mother's $\mathrm{Hb}$ was transformed as $(\mathrm{Hb} \wedge 3) / 1000$ to improve normality of distribution

coverall $P$-value for variable

Nevertheless, the women and children residing in Dagoretti clearly showed better socioeconomic and nutrition status than in Korogocho, and so might be a better model for informal development. The data show that even among low-income households in Nairobi there can be a wide range of variability and hence the importance of stratifying data in urban areas in research and policy design. Some socioeconomic indicators, including livestock ownership, were found to be associated with nutritional outcomes, which is of relevance for policy and intervention design.

\section{Socioeconomic characterisation}

The data (income and family size) indicate that majority of households, in this study live under the World Bank international poverty line set at $1.25 \$$ per day per person [39]. Female-headed households had significantly lower incomes than male-headed households; whereas they were similar comparing other socioeconomic indicators. These results may reflect a misclassification bias. We could not distinguish between female headed households with an absent male-head versus those with no male head. The first named might receive financial support from a husband living away, which could attenuate differences between female and male headed households.

The quality of housing was mostly classified as 'Poor' (i.e. scores $\leq 10$ ), with only a few households being 'Average' (i.e. scores between 11 and 20). All indicators related to ownership of land, domestic assets and animals were better in Dagoretti. Gender disaggregation of asset ownership including livestock is important to identify gender disparities and track potential inequity reduction resulting from targeted interventions. Ownership of assets by women increases the decision power and thus has been associated with positive outcomes in health and education [40]. Assets like livestock can have specific impacts on food access and availability $[41,42]$. The median gender asset disparity was 0.7 , relatively high, indicating female ownership was important. This could be due to the relative presence in the sample of femaleheaded households (one in four households). In addition, the concept of 'ownership' of assets might need further exploration. For example, respondents might say that assets belong to the household and thus to all of its members, but this might not be the case when a couple divorces. In such situations gender disparity could raise, with women losing important assets. A different question formulation could be investigated in this respect in further studies, to obtain more accurate information and assess capacity of women to respond to "household internal shocks' [43].

In this study, $29.3 \%$ of households owned livestock, which is comparable to other African urban settings [44]. Animals are particularly important assets, contributing in multiple ways to household economy, in particular to either income generation and/or the household's own food consumption [44, 45]. The number of heads and species owned can be highly informative to the household's socioeconomic characterisation, and be strongly related to productivity, income and welfare in some rural settings of developing countries. While in rural areas the majority of household keep livestock, the less well-off are more likely 
to keep livestock [44]. In urban areas livestock ownership is generally less common due to space and other restrictions, but the same trend seems to apply [44]. However, these trends can also be context-specific, and African countries such as Malawi or Tanzania have shown that rural wealthier households were likely to own more livestock $[44,46]$. The households keeping livestock in Dagoretti (and an animal biomass (TLH) more than double that of Korogocho) might contribute to a diverse livelihood portfolio, and improve resilience, and dietary quality. However animal concentration can also increase the zoonotic pathogen load in the household. In this study, income was positively associated with animal ownership; this increased income could be either the result of the small-scale livestock production and/or the reason for investment in livestock. Importantly, livestock was reported to be owned predominantly by the household (i.e. not by male members), and also sometimes by women. This deviates from findings in rural poor settlements and may be due to urban context where men can often have a job outside the household and are less involved in livestock. Again there can be differences in the understanding of the term 'ownership', since other work in Dagoretti (among richer dairy households) quoted people as saying "everything with blood in the house belongs to the man", while finding that women dominated decisions about cattle milk, manure and the day-to-day care of cattle [27]. The absence of refrigerators in both areas could pose a challenge to food preservation and food safety, particularly for foods of animal origin (i.e. meat, milk).

\section{Maternal and child nutrition}

The areas under study, like other urban low-income ones, showed the presence of a double burden of malnutrition in which high levels of chronic malnutrition (stunting) co-exist with high levels of maternal overweight/obesity [13]. In this study, 4 in 10 children between 1 and 3 years were stunted and almost one third of their mothers were overweight or obese [14]. Anaemia was also an issue of concern, especially among children, and almost all non-breastfed children were at risk of inadequate iron intakes. The quality of diets was low. Over $50 \%$ of non-breastfed children were at risk of inadequate intakes of iron and calcium; and over $50 \%$ mothers were at risk of inadequate intakes of calcium, zinc, riboflavin and niacin. These nutritional profiles suggest that micronutrient-dense food must be promoted, rather than calorie dense foods, to prevent stunting and reduce overnutrition and its related diseases such as diabetes type II or heart disease. These chronic diseases are becoming prevalent in urban poor settings [47]; and will place an economic burden on health care systems, which might well justify a resource investment in the food production system and in education. Interventions at the food system level may contribute to economic activity as well as prevent long-term reduction in human welfare. Low intakes of essential micronutrients and high rates of stunting and child anaemia justify the promotion of nutrient-dense foods such as animal-source foods. In follow-up research, some related issues were addressed to explore the economic and sociological drivers of animal-source food demand, including price elasticities (Cornelsen L, Dominguez-Salas P, et al. Price and other drivers of demand for animal source foods in peri-urban Nairobi, Kenya. Forthcoming. 2016). These studies also analysed the characteristics of the Nairobi livestock value chains supplying these low-income dwellers, in order to assess associated limitations, challenges, upgrading opportunities and risks (Alarcon P, Fèvre EM, et al. Mapping of the beef, sheep and goat source food systems in Nairobi associated to markets and large processing companies. 2016. Forthcoming).

\section{Children}

Prevalence of stunting above $40 \%$ was 'very high' according to the WHO Classification for assessing severity of child malnutrition, and compared to national levels. This probably reflects long-term problems of food insecurity, poor diets and child feeding practices, micronutrient deficiency, infectious disease load and/or enteropathy, inadequate water and sanitation, among others $[16,17,48]$. Almost one in four children had recently been sick, which might be due to poor food and environmental hygiene and the effect of the rainy season. Malnutrition has consequences for the individual's mental (cognitive) and psychomotor development, and the high prevalence of stunting observed in this study is expected to have serious long-term impact on the development and wellbeing of the Kenyan society as a whole. Tackling stunting in these settings can be challenging, but fostering prevention strategies must be a high priority. Conversely a 'low' level of wasting $(<5 \%)$ was found, which suggests dietary energy intakes were adequate. We observed a sex difference in the prevalence of stunting; however, this was not supported by differential intake in our data. A comparative advantage in girls has been reported in other studies and the reasons could be both biological (response to environmental stress) and cultural (differential access to food, care, or physical activities) $[13,49,50]$. Also, the difference in prevalence between Dagoretti and Korogocho could be related to differences in the general sanitation, population density, and environmental conditions between these two areas. The number of wasted children was not high, but our data showed coexistence of wasting and stunting and an association between them. Both conditions are associated with increased mortality, especially when they coexist, and infectious diseases contribute to both of them, as do inflammation and gut health (via the effects of 
chronic inflammation, malabsorption and/or appetite effects) [51-53]. There is also evidence that weight and length at birth determine later linear (and potentially ponderal) growth, and therefore women should be targeted via maternal (and pre-maternal) health and nutrition support. In children below five years, stunting, severe wasting and intrauterine growth restriction together are estimated to contribute $21 \%$ of total global disability-adjusted life-years (DALYs), which constitutes the largest risk factor in this group [54]. Child anaemia prevalence was above the $40 \%$ WHO anaemia threshold considered as a 'severe public health problem' [38], and does not seem to have improved from data from the latest comprehensive survey on anaemia prevalence in 1999, which was $69.0 \%$ for preschool-age children countrywide [55].

Breastfeeding practices recorded were better than previously reported for these settings [17]; however, the follow up methodology in that study was different: focusing on younger children and with feeding practices being longitudinally recorded in detail. The nutrient intake of children surveyed in Korogocho was consistently lower than those in Dagoretti for all nutrients and child groups, but was only statistically significant in nonbreastfeeding children (with the exception of vitamins A, B12 and C), probably due to the relative sample sizes. B12 was abnormally high in this population probably due to the national mandatory fortification of refined maize flour for the key staple 'ugali'. An increased blood level of vitamin B12 due to high intake is unlikely, as only small amounts of vitamin B12 can be absorbed and the rest is removed in the urine. Therefore, no tolerable upper intake level (UL) has been set [56]. Doses as high as $2000 \mu \mathrm{g}$ have not shown significant side effects [57]. Lower intakes in Korogocho could be due to lower income among the households, although anecdotal observation indicates that food prices are also lower in Korogocho. Also, the access to nutrient-rich value chains could differ among areas. The minimum dietary diversity score was high in Dagoretti compared to studies from other sub-Saharan countries, probably due to the urban nature of the population [58,59], but was significantly lower in Korogocho. In these settings, there is a need to assess if the right quantity and quality of food to ensure dietary requirements can be met with local diets, and thus enable children and women to reach their optimal weight, heights and cognitive capacity. The lack of association between the individual haemoglobin levels and iron intakes might be due to the absence of repeated day intake measurement and inherent measurement error associated with estimating dietary intake, as well as other factors such as parasite infestation. Despite the existence of a programme distributing sprinkles to children under 5 , no household reported consumption of sprinkles within the 24-h recall.

\section{Women}

The prevalence of $29.1 \%$ overweight (9.9 \% obese) in women was lower than previously reported in Korogocho and Viwandani from a sample of older women [60], and coexisted with $7.4 \%$ of women being too thin. The key risk factors for obesity in these areas deserve further investigation and could be related to high intakes of carbohydrates and oil, and to lack of physical activity. The prevalence of anaemia in non-pregnant women was low compared to children but in line with the national prevalence in women of reproductive age (25\%) [61]. Yet, it would still be classified as a 'moderate public health problem'; also, Nairobi has low malaria prevalence. In any case, health policies on anaemia prevention and control introduced by the Ministry of Health over recent years to address the high rates of anaemia need to be formally monitored and evaluated. Taking iron supplements during pregnancy was reported by almost half of the women, although the compliance period was relatively short. Night blindness was also lower than the $6.8 \%$ reported in the $2008 / 09$ demographic and health survey [62] although it is not fully comparable since that study referred to both sexes and to different areas. This was in turn higher than the $4.3 \%$ found in that same survey for rural populations, indicating that dwellers of poor urban areas could have a more limited access to vitamin A rich foods. Nutrient intakes were consistently lower for all nutrients except for vitamin B12 and iron in Korogocho women than in Dagoretti ones, but these differences were only significant for calcium, zinc, riboflavin, vitamin B6 and folate. The significantly higher intake of calcium and riboflavin in Dagoretti could be due to higher fresh milk intakes in this area, possibly facilitated by a higher presence of livestock. Women's dietary diversity indicators were also lower in Korogocho and were in line with previous findings [63]. Ethnicity was not included in the questions to avoid potential sensitivity but it should be explored in the future since dietary practices and patterns have been observed to differ among ethnic groups [64]. A double burden of malnutrition was identified among women, and better nutrition of the woman and child assessed seemed to be associated within households. In addition, higher weight may be related in this population to higher caloric intake from commonly used fried street foods such as 'mandazi' (a sort of doughnut) and oil, and not to good quality foods, thus not preventing stunting or anaemia.

\section{Predictors of malnutrition}

Some factors related to poverty have been identified in previous studies as associated with suboptimal nutrition [65]. Among the sociocultural predictors explored, the best 
predictors of stunting in this study were lower education of the head of the household, sex of the child (with girls having lower stunting rates), and marital status (with married women having more stunted children). Lower education and not being married have been previously identified as risk factors for stunting [12] and breastfeeding cessation [17]. Higher education is likely to be associated with higher knowledge, higher income and more positive health and nutrition practices. Surprisingly, contrary to the previous study, in this sample children of married women were more likely to present lower height-for-age than children of single or divorced women. Although this study includes a different setting (Dagoretti), with a different socioeconomic reality than Korogocho and Viwandani, this finding requires further investigation. Weight-for-height showed positive relationship with female livestock ownership expressed as number of tropical livestock units, suggesting a beneficial effect of women owning animals as regards wasting in these settings, although this association was only marginally significant and would require further study. Evidence so far has shown that animal ownership may relate to better nutrition at household level [45, 66-68]; this has been reported for stunting in rural populations, and the pathways are still unclear. The lack of association of stunting with animal assets in this sample might thus be due to different dynamics of animal use and expenditure patterns in these urban areas compared to rural ones. In poor urban settings, direct pathways contributing to own consumption of animal-source foods could be affected due to animals being kept far from households (in this sample, households with higher number of animals i.e. $>5$ heads of ruminants or $>10$ heads of poultry were kept mostly outside the urban area) and therefore contribution to daily intakes might be limited, or alternatively to fewer animals kept. Indirect pathways of income generation to purchase food might also be affected due to a higher number of competing priorities for money expenditure. In addition, animals in overcrowded areas could contribute more easily to zoonotic disease via environmental contamination, potentially contributing to malnutrition. Therefore, the interaction with animals in these settings could be substantially different to rural areas and deserves further investigation. The association found with wasting rather than with stunting could be due to the sale of animal-source foods to buy caloric foods (staples, oil, etc.) rather than for own consumption. The negative association of income with weight-for-height and maternal BMI was unexpected. It is important to note that the difference between income categories is limited, and households may have varied among income category each month, as incomes were often irregular. Again, this finding might be related to expenditure dynamics: when additional income was obtained in a month, it might have been diverted to other household needs, reducing intakes. The fact that it was not associated with longer-term indicators such as height-for-age is reasonable when income differences are not related to higher level of education or knowledge, as adequate height-for-age at young age does not only rely on sufficient quantity of intake but also on quality of diet and good weaning food practices. Anaemia was not strongly related to any of the factors, and the effect of other factors such as intestinal parasites might be more important. The lack of association of nutrition with domestic assets might be related to the choice of assets, whose ownership might not be meaningful enough in these settings as to characterise different types of households (for example, in an urban area certain assets such as second-hand radio or a cooker might be easier to obtain at an affordable price; so which might be the best indicators for this type of context deserves attention).

\section{Limitations}

The households visited were relatively homogeneous in terms of socioeconomic parameters, and the range restriction might make it more difficult to establish differences. It must be noted that levels of acute malnutrition and BMI could substantially differ throughout the year, where different food availability, prices and access, and ultimately intake, as well as a different pattern of diseases are likely. Specifically, this study took place at the end of the short rainy season and weight could have been lower due to increased infections (respiratory infection, diarrhoea, etc., particularly in children) resulting, for example, from poor structures for water and sanitation and associated flooding. Also, as noted, part of the data was collected prior to Christmas festivities and part after, when purchase power may be lower. Although there was a two-week interruption to ensure a wash out period, weight might have been affected by festivities, when trips to rural areas are frequent (potentially with access to more diverse foods), as well as having relatives visiting for celebrations, and better meals and higher intakes. Data collection throughout the year would help obtain a better picture of the nutrition situation and capture seasonal variations. In any case, dietary data are subject to bias arising from recall, the error introduced by FCTs, and both respondent's underreporting and over-reporting, which are expected to balance out on average, but may be important at individual level. Also, more than one day of observation would have been preferable to capture the intra-individual variation. A specific difficulty in a setting where food is often sold in small repacked portions is the misclassification of certain foods (e.g. flour composition, oil type). Finally the limited sample size might have prevented detection of statistically significant small differences and association. The necessary division between breastfed and non-breastfed children reduced further the sample size in some of the child comparisons. 


\section{Conclusions}

This study presents useful information on socioeconomic and nutrition characteristics in two low-income urban areas of Nairobi. It highlights several key points: a) the two lowincome areas investigated (Dagoretti, urban area with lower population density and more agriculture activities, and Korogocho, a shanty town inside the city) differed substantially, with Dagoretti showing consistently better indicators. This suggests that Dagoretti might represent a better model for informal development where, for example, the high proportion of households keeping livestock in Dagoretti could be contributing to a more diverse livelihood portfolio and to improved resilience. In any case, differences among low-income areas need to be considered when planning and prioritising interventions; b) there is evidence of triple burden of malnutrition, with 4 in 10 children stunted, 3 in 10 mothers obese, and high prevalence of anaemia, emphasising the need to target nutrition interventions and to address quality as well as quantity; c) livestock keeping was not found to be associated with stunting, which contrasts the results from recent studies that showed that livestock keeping in rural areas is associated with better stunting reduction; it was however marginally associated with wasting. This suggests that the livestock path to nutrition may be different in urban and rural contexts. Therefore, to improve nutrition during the first 1000 days in these settings, market based interventions may be more promising than interventions targeting livestock production. Upscaling of food value chain interventions could potentially contribute to ensure an affordable nutrient-dense food supply for healthy and sustainable diets. Interventions also need to incorporate women's empowerment and gender equality as a cross-cutting issue. Particularly for some gender indicators, such as women ownership of livestock and decision-making, further research is needed in this setting, including qualitative research. Given that urban populations are expected to expand in the coming years, these lowincome settings will require further investigation to inform and develop policies and interventions with positive impact on maternal and child nutrition.

\section{Additional file}

Additional file 1: Table S1. Socioeconomic characteristics of participant households, by sex of household-head. Table S2: Nutritional indicators of participant children and women in poor households of Nairobi, by gender characteristics. Table S3: Coefficients of the univariable regression analysis for predictors of interest of nutritional outcomes. (DOCX $51 \mathrm{~kb}$ )

\section{Acknowledgements}

We thank the women of Dagoretti and Korogocho who patiently participated in the study. We are also grateful to the Kenyan field team (Douglas Angogo, Gideon Mwangi, Judith Mwangangi and Emma Osoro); the health staff at central and local level; Carlos Quiros, Jason Rogena, Jusper
Kiplimo, and James Akoko, from ILRI for designing the CSPro application, the ODK system, the maps, and for the advice on logistics respectively; Edgar Onyango from Hellen Keller international for his help with organising the survey. We also thank the support from the African Population and Health Research Centre (APHRC) team, whose study site is supported by the William and Flora Hewlett Foundation (general support), Bill and Melinda Gates foundation (DSS) and SIDA (Swedish International Development cooperation Agency). The FCT and Photobooks used were compiled by Micronutrient Initiative and Kenya Medical Research Institute - Centre for Public Health Research via a grant by The Micronutrient Initiative. IMAPP software (Intake Modelling, Assessment and Planning Program) was developed by Alicia Carriquiry (lowa State University), Suzanne Murphy (University of Hawaii Cancer Research Centre) and Lindsay Allen (USDA Western Human Nutrition Research (entre) in collaboration with Bruno de Benoit and Lisa Rogers (World Health Organization) with funding from WHO.

\section{Funding}

This project was conducted with funding from the CGIAR Research Program on Agriculture for Nutrition and Health $(\mathrm{A} 4 \mathrm{NH})$ lead by the International Food Policy Research Institute (IFPRI), the International Livestock Research Institute (ILRI), the Medical Research Council, Natural Environment Research Council, Economic and Social Research Council, Biotechnology and Biosciences Research Council through the Environmental \& Social Ecology of Human Infectious Diseases Initiative (ESEI), Grant Reference: G1100783/1, and the Leverhulme Centre for Integrative Research in Agriculture and Health (LCIRAH).

\section{Availability of data and materials}

Data and analysis codes are available from the authors upon request and will be deposited in ILRI's publicly available repository at the end of the study.

\section{Authors' contributions \\ The authors' responsibilities were as follows: $P A, K C, E F, E F, D G, B H$ and JR conceived the study; PA, SA, KC, PD-S, EF, EF, DG, BH, EWK-M and JR contributed to the study protocol; PD-S conducted the data collection; ID and PD-S performed the statistical analysis; and PD-S drafted the manuscript. All authors reviewed and approved the final manuscript.}

\section{Competing interests}

The authors declare that they have no competing interests.

Consent for publication

No individual participant data is published.

\section{Ethics approval and consent to participate}

Ethical approval was granted by the International Livestock Research Institute Institutional Research Ethics Committee (ILRI-IREC2013-14), recognised by Kenyan authorities as competent to provide ethical clearance for human research in Kenya, and the Royal Veterinary College Ethics Committee (URN2013 0093H) in the United Kingdom. Informed written consent was obtained from all respondents after health authorities approval at the community level.

\section{Author details}

${ }^{1}$ Veterinary Epidemiology, Economics and Public Health Group, Royal Veterinary College, University of London, Hawkshead Lane, Hatfield, Hertfordshire AL9 7TA, UK. ${ }^{2}$ International Livestock Research Institute, Old Naivasha Rd, Nairobi 00100, Kenya. ${ }^{3}$ Leverhulme Centre for Integrated Research on Agriculture and Health, 36 Gordon Square, London WC1H OPD, UK. ${ }^{4}$ Department of Health Management, Atlantic Veterinary College, University of Prince Edward Island, Charlottetown PEI C1A 4P3, Canada. ${ }^{5}$ FAS Global, 2039 McCarty Hall, University of Florida, Gainesville, Florida 32611, USA. ${ }^{6}$ African Population and Health Research Center, P.O. Box 10787-00100, Nairobi, Kenya. ${ }^{7}$ Department of Population Health, London School of Hygiene and Tropical Medicine, Keppel St, London WC1E 7HT, UK. ${ }^{8}$ Institute of Infection and Global Health, University of Liverpool, Leahurst Campus, Neston CH64 7TE, UK.

Received: 16 March 2016 Accepted: 19 July 2016

Published online: 05 August 2016 


\section{References}

1. WHO. Millennium Development Goals. Factsheet2015.

2. UN. The millennium development goals report. 2015 .

3. Webb P. Nutrition and the post-2015 sustainable development goals. A policy brief. Geneva: UNSCN Secretariat; 2014.

4. Black RE, Victora CG, et al. Maternal and child undernutrition and overweight in low-income and middle-income countries. Lancet. 2013;382(9890):427-51.

5. UNICEF. The state of the world's children. Focus on nutrition. 1998.

6. Bhutta ZA, Das JK, et al. Evidence-based interventions for improvement of maternal and child nutrition: what can be done and at what cost? Lancet. 2013;382(9890):452-77.

7. Smith LC, Haddad L. Reducing child undernutrition: past drivers and priorities for the post-MDG Era. Brighton, UK: Institute of Development Studies Working paper; 2014

8. Gilbert A. The return of the slum: does language matter. Int J Urban Region Res. 2007;31.4(December):697-713.

9. UN-Habitat. What are the slums and why do they exist? 2007.

10. APHRC. Population and Health Dynamics in Nairobi's Informal Settlements: Report of the Nairobi Cross-sectional Slums Survey (NCSS) 2012. Nairobi, Kenya: African Population and Health Research Centre; 2014.

11. KNBS. Demographic and health survey. Key indicators. Nairobi, Kenya: Kenya National Bureau of Statistics; 2014.

12. Abuya BA, Ciera J, et al. Effect of mother's education on child's nutritional status in the slums of Nairobi. BMC Pediatr. 2012;12:80.

13. Olack $B$, Burke $H$, et al. Nutritional status of under-five children living in an informal urban settlement in Nairobi, Kenya. J Health Popul Nutr. 2011;29(4):357-63.

14. Kimani-Murage EW, Muthuri SK, et al. Evidence of a double burden of malnutrition in urban poor settings in Nairobi, Kenya: UN-Habitat. PLoS One. 2015;10(6):e0129943.

15. UN-Habitat. Slums of the World. The Face of Urban Poverty in the New Millennium?. Nairobi, Kenya: 2003.

16. Kimani-Murage EW, Schofield L, et al. Vulnerability to food insecurity in urban slums: experiences from Nairobi, Kenya. J urban health. 2014;91(6):1098-113.

17. Kimani-Murage EW, Madise NJ, et al. Patterns and determinants of breastfeeding and complementary feeding practices in urban informal settlements, Nairobi Kenya. BMC Public Health. 2011:11:396.

18. Mutua MK, Kimani-Murage $E$, et al. Childhood vaccination in informal urban settlements in Nairobi, Kenya: who gets vaccinated? BMC Public Health. 2011;11(1):6.

19. Kimani-Murage EW, Ngindu AM. Quality of water the slum dwellers use: the case of a Kenyan slum. J urban health. 2007;84(6):829-38.

20. Smith LC, Haddad L. Explaining child malnutrition in developing countries: A cross-country analysis. International Food Policy Research Institute. 1999

21. Van den Bold M, Quisumbing AR, et al. Discussion paper on Women's empowerment and nutrition. Washington, D.C: International Food Policy Research Institute; 2013.

22. Smith LC, Ramakrishnan U, et al. The Importance of Women's Status for Child Nutrition in Developing Countries. International Food Policy Research Institute. 2003

23. Quisumbing AR. Household decisions, gender, and development: a synthesis of recent research. Washinton, DC: International Food Policy Research Institute; 2003.

24. James $A E$, Palmer $\mathrm{GH}$. The role of animal source foods in improving nutritional heatlh in urban informal settlements: identification of knowledge gaps and implementation barrier. Int J Child Health Nutr. 2015:4:94-102.

25. Randolph TF, Schelling E, et al. Invited review: Role of livestock in human nutrition and health for poverty reduction in developing countries. J Anim Sci. 2007:85(11):2788-800.

26. 2009 Census. Population, households and density 2009. Available from: https://www.opendata.go.ke/page/about.

27. Kang'ethe EK, Kimani VN, et al. A trans-disciplinary study on the health risks of cryptosporidiosis from dairy systems in Dagoretti, Nairobi, Kenya: study background and farming system characteristics. Trop Anim Health Prod 2012:44 Suppl 1:S3-10.

28. Beguy D, Elung'ata $P$, et al. Health \& demographic surveillance system profile: the Nairobi urban health and demographic surveillance system (NUHDSS). Int J Epidemiol. 2015;44(2):462-71.

29. Njuki J, Poole J, et al. Gender, Livestock and Livelihood Indicators. International Livestock Research Institute. 2011
30. Gibson RS, Ferguson EL. An interactive 24-hour recall for assessing the adequacy of iron and zinc intakes in developing countries. Washington DC: International Life Sciences Institute; 2008.

31. Ferguson $\mathrm{E}$, Chege $\mathrm{P}$, et al. Zinc, iron and calcium are major limiting nutrients in the complementary diets of rural Kenyan children. Maternal child nutr. 2015;11 Suppl 3:6-20.

32. Hotz C, Lubowa A, et al. A Food Composition Table for Central and Eastern Uganda. In: HarvestPlus, editor. Washington, DC: Technical Monograph:2012.

33. Dewey $\mathrm{KG}$, Brown $\mathrm{KH}$. Update on technical issues concerning complementary feeding of young children in developing countries and implications for intervention programs. Food Nutr Bull. 2003;24(1):5-28.

34. Kennedy G, Ballard T, et al. Guidelines for measuring household and individual dietary diversity. 2013.

35. WHO. Indicators for assessing infant and young child feeding practices (Part I Definitions). 2007.

36. Bloem M. The 2006 WHO child growth standards. BMJ. 2007;334(7596):705-6.

37. WHO. Physical status: the use and interpretation of anthropometry. Geneva: World Health Organisation; 1995

38. WHO. Iron deficiency anaemia: assessment, prevention, and control. A guide for programme managers. Geneva: World Health Organisation; 2001

39. Ravallion M, Chen S, Sangraula P. Dollar a Day Revisited World Bank Econ Rev. 2009;23(2):163-184. first published online June 26, 2009 doi:10.1093/ wber/lhp007.

40. Quisumbing AR, McClafferty B. Using Gender Research in Development. International Food Policy Research Institute. Washington, DC; 2006.

41. Strategy and plan of action to mainstream gender in ILRI. International Livestock Research Institute, Nairobi, Kenya; 2012.

42. FAO. The State of Food and Agriculture 2010-11. Women in Agriculture Closing the gender gap for development; 2011.

43. Galiè A, Mulema A, Benard MM, Onzere SN, Colverson KE. Exploring gender perceptions of resource ownership and their implications for food security among rural livestock owners in Tanzania, Ethiopia, and Nicaragua. Agri Food Sec. 2015;4(2). doi:10.1186/s40066-015-0021-9.

44. Pica-Ciamarra U, Tasciotti L, et al. Livestock in the household economy: Crosscountry evidence from microeconomic data. Dev Pol Rev. 2015;33(1):61-81.

45. Cross E, Azzarri C, et al. Does Livestock Ownership Affect Animal Source Foods Consumption and Child Nutritional Status? Evidence from Rural Uganda. 2014

46. Covarrubias K, Nsiima L, et al. Livestock and livelihoods in rural Tanzania. A descriptive analysis of the 2009 National Panel Survey. Joint paper of the Wrold Bank, FAO, AU-IBAR, ILRI and the Tanzania Ministry of Livestock and Fisheries Development, 2012

47. Oti SO, van de Vijver SJ, et al. The magnitude of diabetes and its association with obesity in the slums of Nairobi, Kenya: results from a cross-sectional survey. Tropical med int health. 2013;18(12):1520-30.

48. Kimani-Murage EW, Holding PA, et al. Food security and nutritional outcomes among urban poor orphans in Nairobi, Kenya. J urban health 2011:88 Suppl 2:S282-97.

49. Keino S, Plasqui G, et al. Determinants of stunting and overweight among young children and adolescents in sub-Saharan Africa. Food Nutr Bull. 2014; 35(2):167-78.

50. Wamani $\mathrm{H}$, Astrom AN, et al. Boys are more stunted than girls in subSaharan Africa: a meta-analysis of 16 demographic and health surveys. BMC Pediatr. 2007;7:17

51. Rytter MJ, Kolte $L$, et al. The immune system in children with malnutrition-a systematic review. PLoS One. 2014:9(8):e105017.

52. Briend $A$, Khara T, et al. Wasting and stunting-similarities and differences: policy and programmatic implications. Food Nutr Bull. 2015;36(1 Suppl):S15-23.

53. Richard SA, Black RE, et al. Diarrhea in early childhood: short-term association with weight and long-term association with length. Am J Epidemiol. 2013;178(7):1129-38.

54. Black RE, Allen LH, et al. Maternal and child undernutrition: global and regional exposures and health consequences. Lancet. 2008:371(9608):243-60.

55. WHO/CDC. Worldwide prevalence of anaemia 1993-2005. WHO Global Database on Anaemia 2008

56. Dietary Reference Intakes for thiamin, riboflavin, niacin, vitamin B6, folate, vitamin B12, pantothenic acid, biotin, and choline. Washington, D.C.: National Academy of Sciences, 2000.

57. Kuzminski AM, Del Giacco EJ, et al. Effective treatment of cobalamin deficiency with oral cobalamin. Blood. 1998;92(4):1191-8.

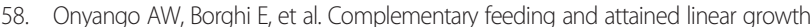
among 6-23-month-old children. Public Health Nutr. 2014;17(9):1975-83. 
59. Na M, Jennings $L$, et al. Association between women's empowerment and infant and child feeding practices in sub-Saharan Africa: an analysis of demographic and health surveys. Public Health Nutr. 2015;18(17):3155-65.

60. Ettarh R, Van de Vijver S, et al. Overweight, obesity, and perception of body image among slum residents in Nairobi, Kenya, 2008-2009. Prev Chronic Dis. 2013;10:E212.

61. Global Nutrition Report 2015. Actions and accountability to advance nutrition and sustainable development. Washington DC: International Food Policy Research Institute; 2015.

62. KNBS. Kenya Demographic and Health Survey. 2010.

63. Steyn NP, Nel JH, et al. Urbanisation and the nutrition transition: a comparison of diet and weight status of South African and Kenyan women. Scandinavian j public health. 2012;40(3):229-38.

64. Hansen AW, Christensen DL, et al. Dietary patterns, food and macronutrient intakes among adults in three ethnic groups in rural Kenya. Public Health Nutr. 2011;14(9):1671-9.

65. Lang'o DB. Social determinants of child under-nutrition in urban informal settlements in Kenya. 2011

66. Mosites EM, Rabinowitz PM, et al. The relationship between livestock ownership and child stunting in three countries in Eastern Africa using national survey data. PLoS One. 2015;10(9):e0136686.

67. Herrador Z, Sordo L, et al. Cross-sectional study of malnutrition and associated factors among school aged children in rural and urban settings of Fogera and Libo Kemkem districts, Ethiopia. PLoS One. 2014;9(9):e105880.

68. Shinsugi $C$, Matsumura $M$, et al. Factors associated with stunting among children according to the level of food insecurity in the household: a crosssectional study in a rural community of Southeastern Kenya. BMC Public Health. 2015;15:441.

\section{Submit your next manuscript to BioMed Central and we will help you at every step:}

- We accept pre-submission inquiries

- Our selector tool helps you to find the most relevant journal

- We provide round the clock customer support

- Convenient online submission

- Thorough peer review

- Inclusion in PubMed and all major indexing services

- Maximum visibility for your research

Submit your manuscript at www.biomedcentral.com/submit 